\title{
Knockdown of Salusin- $\beta$ Improves Cardiovascular Function in Myocardial Infarction-Induced Chronic Heart Failure Rats
}

\author{
Yu Xu, ${ }^{1,2}$ Yan Pan, ${ }^{1,2}$ Xingxing Wang, ${ }^{1,2}$ Aidong Chen, ${ }^{1,2}$ Xinyu Tang, ${ }^{1,2}$ Xuanxuan Liu, ${ }^{3}$ \\ and Ying Han $\mathbb{1}^{1,2}$ \\ ${ }^{1}$ Key Laboratory of Targeted Intervention of Cardiovascular Disease, Collaborative Innovation Center of Translational Medicine for \\ Cardiovascular Disease, Nanjing Medical University, Nanjing, Jiangsu 211166, China \\ ${ }^{2}$ Department of Physiology, Nanjing Medical University, Nanjing, Jiangsu 211166, China \\ ${ }^{3}$ Department of Physiology and Pathologic Physiology, Kangda College of Nanjing Medical University, Lianyungang, \\ Jiangsu 222000, China
}

Correspondence should be addressed to Ying Han; yhancn@njmu.edu.cn

Received 12 August 2020; Revised 22 June 2021; Accepted 2 July 2021; Published 11 August 2021

Academic Editor: Qingping Feng

Copyright (C) $2021 \mathrm{Yu} \mathrm{Xu}$ et al. This is an open access article distributed under the Creative Commons Attribution License, which permits unrestricted use, distribution, and reproduction in any medium, provided the original work is properly cited.

\begin{abstract}
Salusin- $\beta$ is a biologically active peptide with 20 amino acids that exerts several cardiovascular activity-regulating effects, such as regulating vascular endothelial function and the proliferation of vascular smooth muscle cells. However, the regulatory effects of salusin- $\beta$ in myocardial infarction-induced chronic heart failure (CHF) are still unknown. The current study is aimed at investigating the effects of silencing salusin- $\beta$ on endothelial function, cardiac function, vascular and myocardial remodeling, and its underlying signaling pathways in CHF rats induced by coronary artery ligation. CHF and sham-operated (Sham) rats were subjected to tail vein injection of adenoviral vectors encoding salusin- $\beta$ shRNA or a control-shRNA. The coronary artery (CA), pulmonary artery (PA), and mesenteric artery (MA) were isolated from rats, and isometric tension measurements of arteries were performed. Compared with Sham rats, the plasma salusin- $\beta$, leptin and visfatin levels and the salusin- $\beta$ protein expression levels of CA, PA, and MA were increased, while the acetylcholine- (ACh-) induced endothelium-dependent vascular relaxation of CA, PA, and MA was attenuated significantly in CHF rats and was improved significantly by salusin- $\beta$ gene knockdown. Salusin- $\beta$ knockdown also improved cardiac function and vascular and myocardial remodeling, increased endothelial nitric oxide synthase (eNOS) activity and nitric oxide (NO) levels, and decreased NAD(P)H oxidase activity, NOX-2 and NOX-4 expression, and reactive oxygen species (ROS) levels in arteries in CHF rats. The effects of salusin- $\beta$ knockdown in CHF rats were attenuated significantly by pretreatment with the NOS inhibitor L-NAME. These results indicate that silencing salusin- $\beta$ contributes to the improvement of endothelial function, cardiac function, and cardiovascular remodeling in CHF by inhibiting $\mathrm{NAD}(\mathrm{P}) \mathrm{H}$ oxidase-ROS generation and activating eNOS-NO production.
\end{abstract}

\section{Introduction}

Chronic heart failure (CHF) is the terminal stage of a variety of cardiovascular diseases and is characterized by progressive left ventricular dysfunction and declining ejection fraction (EF), usually accompanied by vascular endothelial dysfunction, neuroendocrine activation, and ventricular remodeling [1-3]. Among them, vascular endothelial dysfunction usually occurs at the early stages of heart failure and is closely related to the development of $\mathrm{CHF}$ and is also a predictor of adverse events, such as cardiovascular remodeling in CHF patients
$[4,5]$. Normally, vascular endothelial cells (VECs) can release vasoconstrictor factors, such as endothelin-1, and vasodilatation factors, such as nitric oxide (NO), endothelium-derived hyperpolarizing factor (EDHF), and prostaglandin (PGI2), to control vascular tone. When endothelial dysfunction occurs, the release of vasoconstrictor factors and vasodilatation factors from VECs becomes imbalanced. Among these, the decrease in NO bioavailability plays the most important role in CHF [6-8], which results in the decline of vascular relaxation and the increase in vascular contraction function $[9$, 10]. Attenuated vascular relaxation caused by endothelial 
dysfunction in the coronary artery (CA) in CHF decreases vascular compliance, reduces the blood supply to the heart, and subsequently causes myocardial ischemia and angina and further deterioration of cardiac function [11, 12]. Attenuated pulmonary artery (PA) relaxation in CHF increases pulmonary vascular resistance and might contribute to the high incidence of pulmonary hypertension due to left heart disease $[13,14]$. Due to the enormous quantity of mesenteric artery (MA), attenuated MA relaxation increases peripheral resistance and cardiac afterload, leading to further cardiac dysfunction. It is necessary to find therapeutic methods or interventions to correct the endothelial dysfunction of heart failure and then improve cardiac function and prevent the progression of CHF. Acetylcholine (ACh) stimulates VECs to release $\mathrm{NO}$ and induces vascular smooth muscle cells (VSMCs) relaxation. Leptin and visfatin, which are involved in regulating endothelial function and NO-dependent vasorelaxation, have been proposed as clinical markers of endothelial dysfunction and vascular injury in cardiovascular diseases [15-17]. Therefore, measurements of ACh-induced vasodilatation and plasma leptin and visfatin levels are usually used to evaluate endothelial function.

The salusin family includes salusin- $\alpha$ and salusin- $\beta$, which are translated from the alternative spliced mRNA of torsin family 2 member A (TOR2A) [18-20]. Salusin- $\beta$ is an endogenous biologically active polypeptide with 20 amino acids, and salusin- $\alpha$ has 28 amino acids. Compared to salusin- $\alpha$, salusin $-\beta$ is more closely related to cardiovascular diseases. Salusin- $\beta$ is expressed abundantly in peripheral vascular tissue, including VECs and VSMCs [21-23]. Even though studies have found that salusin- $\beta$ might be a ligand of the mas-like $\mathrm{G}$ protein-coupled receptor or $\beta$ chain of ATP synthase [24-26], its exact receptor has not yet been discovered or confirmed. It has been reported that salusin- $\beta$ regulates blood pressure [27], activates sympathetic outflow [28], and promotes the proliferation, migration, and foam cell formation of VSMCs [29-31]. More importantly, salusin- $\beta$ is closely related to vascular endothelial function $[29,32]$. Studies have found that salusin- $\beta$ is involved in endothelial injury and dysfunction in diabetes mellitus $[30,33]$. Recently, we also found that salusin- $\beta$ plays important roles in regulating endothelial dysfunction in spontaneously hypertensive rats [34, 35]. It has been reported that salusin- $\beta$ expression in the paraventricular nucleus (PVN) in aged spontaneously hypertensive rats with heart failure is dramatically increased, and salusin- $\beta$ knockdown in the PVN attenuates sympathetic excitation and hypothalamic inflammation as well as cardiac and vascular dysfunction [36]. However, whether the salusin- $\beta$ level is also increased and whether salusin- $\beta$ contributes to endothelial dysfunction and impaired cardiovascular function in myocardial infarction-induced CHF are still unknown.

Therefore, the present study was designed to determine whether salusin- $\beta$ plays roles in regulating endothelial dysfunction, cardiovascular remodeling, and cardiac function by silencing salusin- $\beta$, and to explore its downstream molecular mechanisms in three important small arteries, CA, PA, and MA, of CHF and sham-operated (Sham) rats.

\section{Materials and Methods}

The experiments were carried out on male Sprague-Dawley rats that were housed in a temperature- and humiditycontrolled animal room on a $12 \mathrm{~h}-12 \mathrm{~h}$ light to dark cycle with free access to standard chow and tap water. The procedures were approved by the Nanjing Medical University Experimental Animal Care and complied with the Guide for the Care and Use of Laboratory Animals published by the US National Institutes of Health (NIH publication, 8th edition, 2011).

2.1. Model of CHF. The myocardial infarction-induced $\mathrm{CHF}$ model was established by coronary artery ligation, as described in our previous studies [37,38]. Briefly, the left coronary artery of rats weighing approximately $180 \mathrm{~g}$ was ligated near the point at which it branched off from the aorta. Approximately $20 \%$ of the animals died, and death occurred mainly during the first day after ligation. The Sham rats were treated in the same way as the CHF rats, except their coronary arteries were not ligated. Six to eight weeks after coronary ligation, the degree of CHF was assessed. The defined criteria for $\mathrm{CHF}$ were an elevated left ventricular enddiastolic pressure (LVEDP) (>13 $\mathrm{mmHg}$ ) and a $40 \%$ decrease in the maximum first derivative of left ventricular pressure $\left(\mathrm{LV}+\mathrm{dP} / \mathrm{dt}_{\max }\right)$.

2.2. Silencing of Salusin- $\beta$. CHF and Sham rats underwent tail intravenous injection of adenoviral vectors encoding control shRNA or salusin- $\beta$ shRNA $\left(2 \times 10^{11}\right.$ plaque forming units/mL, constructed by Genomeditech Co. Shanghai, China) to knockdown salusin- $\beta$ as previously reported [27]. After 2 weeks, specific knockdown of salusin- $\beta$ was verified by measuring salusin- $\beta$ levels in plasma and protein expression in the CA, PA, and MA of rats by using Western blot.

2.3. Echocardiographic Assessment of Left Ventricular (LV) Function. Echocardiography was performed under ketamine $(25 \mathrm{mg} / \mathrm{kg}$, ip) sedation using an ultrasound system (Vevo 2100 , Visual Sonics, Canada) and a $21 \mathrm{MHz}$ probe to evaluate LV function after salusin- $\beta$ knockdown as we previously described [37]. The following parameters were measured: left ventricular end-diastolic diameter and systolic diameter (LVEDD and LVESD, respectively), interventricular septal thickness in diastole and systole (IVSd and IVSs, respectively), and left ventricular posterior wall thickness in diastole and systole (LVPWd and LVPWs, respectively). Left ventricular fractional shortening (FS) and ejection fraction (EF) were calculated. All measures were averaged over four consecutive cardiac cycles.

2.4. Hemodynamic Parameters Measurement. Two weeks after control or salusin- $\beta$-shRNA application, rats were intraperitoneally anesthetized with urethane $(800 \mathrm{mg} / \mathrm{kg})$ and $\alpha$-chloralose $(40 \mathrm{mg} / \mathrm{kg})$ after weighing. First, the right carotid artery was cannulated and connected to a pressure transducer (MLT0380, ADInstruments, Australia) to record continuous arterial blood pressure. The systolic arterial pressure (SAP), diastolic arterial pressure (DAP), pulse pressure $(\mathrm{PP})$, mean arterial pressure (MAP), and heart rate (HR) 
were then calculated. Next, the catheter was pushed into the left ventricle from the right carotid artery to record LV pressure. The LV peak systolic pressure (LVSP), LVEDP, $\mathrm{LV}$ developed pressure (LVDP), and $\mathrm{LV}+\mathrm{dP} / \mathrm{dt}_{\max }$ were calculated.

2.5. Isometric Tension Measurements in Arteries. Isometric tension of arteries was measured to evaluate vascular endothelial function as described in our previous report [39]. Briefly, after hemodynamic parameters were measured, the heart, lung, and mesentery were isolated from rats. Heart weight and infarct size were measured. Then, the thirdorder CA, PA, and MA were isolated and cut into 1-1.2 mm segments. Arterial rings (1 arterial ring/artery/rat was used) were mounted in a four-chambered myograph $(620 \mathrm{M}$, DMT, Denmark) with $20 \mu \mathrm{m}$ wires and set at a resting tension of $0.1 \mathrm{~g}$. After arterial ring contraction induced by prostaglandin F2 $\alpha$ (PGF $2 \alpha$ ), six doses of ACh $\left(10^{-9} \sim 10^{-4} \mathrm{~mol} / \mathrm{L}\right)$ were administered in a dose-dependent manner to induce vascular relaxation. The degree of relaxation is shown as a percentage of PGF $2 \alpha$-induced contraction.

2.6. Treatment with L-NAME in CHF Rats. The nitric oxide synthase (NOS) inhibitor L-NAME $(50 \mathrm{mg} / \mathrm{kg} /$ day) was given to rats by gavage for four weeks. The control group was given saline. At the start of the third week of L-NAME application, knockdown of salusin- $\beta$ was performed.

2.7. Measurement of Protein Expression in Arteries by Western Blot. Third-order CA, PA, or MA samples were isolated from rats, flash-frozen in liquid nitrogen, and stored at $-70^{\circ} \mathrm{C}$. Then, the artery tissues were homogenized and centrifuged. The tissue homogenate from the artery was subjected to Western blot analysis for determination of protein levels. The protein concentration was measured using a protein assay kit (BCA, Pierce, USA), loaded onto an SDS-PAGE gel, and then transferred to a polyvinylidene fluoride membrane. The membranes were then probed overnight at $4^{\circ} \mathrm{C}$ with anti-salu$\sin -\beta \operatorname{IgG}(1: 1000$, Clound-Clone Corp, USA), endothelial NOS (eNOS) antibody ( $1: 1000$, Cell Signaling Technology, USA), phospho-eNOS Ser1177 antibody $(1: 1000$, Cell Signaling Technology, USA), NOX-2 antibody ( $1: 1000$, Abcam, USA), NOX-4 antibody ( $1: 1000$, Proteintech Inc., Wuhan, China), or $\beta$-actin antibody (1:5000, Abways Technology Inc., Shanghai, China) followed by incubation with horseradish peroxidase-conjugated goat anti-rabbit IgG (1:5000, Immunology Consultants Lab, Portland, OR, USA). Protein loading was controlled by probing all blots with $\beta$-actin antibody. The bands were visualized by an enhanced chemiluminescence ECL system (Pierce Chemical, Rockford, IL, USA). eNOS activity was evaluated by the ratio of phosphorylation of eNOS to total eNOS (p-eNOS/T-eNOS).

2.8. Measurement of Salusin- $\beta$, Leptin, Visfatin, eNOS, NO Levels, and eNOS Activity by ELISA. Commercial ELISA kits were used for the measurement of the plasma salusin- $\beta$ (Cloud-clone corp, Wuhan, China), leptin (Hui Jia Biotechnology, Xiamen, China), visfatin (Hui Jia Biotechnology, Xiamen, China), and eNOS levels of arteries (Yi Fei Xue Biotechnology, Nanjing, China) according to the manufac- turer's descriptions. A nitrate/nitrite colorimetric assay kit (Cayman Chemical Co., Ann Arbor, MI, USA) was used to evaluate NO production in arteries based on the detection of the concentration of its stable metabolites nitrate and nitrite. The measurement of eNOS activity by ELISA was performed using a Nitric Oxide Synthase Assay Kit (Beyotime Biotech Inc., Nanjing, China) by assessing the ability of conversion of L-arginine to NO.

2.9. Measurement of $N A D(P) H$ Oxidase Activity and Reactive Oxygen Species (ROS) Levels. NAD(P)H oxidase activity and ROS levels were measured using the enhanced lucigeninderived chemiluminescence method as we previously reported [27, 40-42]. Briefly, the light emissions produced by the reactions between lucigenin $(5 \mu \mathrm{M})$ and the ROS in tissue homogenate supernatant were measured by a luminometer (20/20n, Turner, CA, USA) once every minute for 10 minutes to measure ROS levels. To measure $\mathrm{NAD}(\mathrm{P}) \mathrm{H}$ oxidase activity, $\mathrm{NAD}(\mathrm{P}) \mathrm{H}(100 \mu \mathrm{M})$ was first added to the medium as a substrate to react with $\mathrm{NAD}(\mathrm{P}) \mathrm{H}$ oxidase to generate ROS before the reactions between lucigenin and ROS were detected by a luminometer. The values representing $\mathrm{NAD}(\mathrm{P}) \mathrm{H}$ oxidase activity and ROS levels are expressed as the mean light unit (MLU) per minute per milligram of protein.

2.10. Evaluation of Vascular Remodeling. Third-order CA, $\mathrm{PA}$, and MA isolated from rats were embedded in paraffin, cut into $5-\mu \mathrm{m}$ thick cross-sections, and stained with hematoxylin-eosin (HE). The structural changes of these arteries were observed with a light microscope. The media thickness, lumen diameter, and media thickness/lumen diameter were measured and used as indexes of vascular remodeling [27].

2.11. Evaluation of Left Ventricular Remodeling and Microvascular Density. Perivascular fibrosis in the intramuscular arteries and arterioles and myocardium fibrosis were evaluated in Masson's trichrome-stained sections under high and low power microscope as previously reported [27, 43]. Myocyte cross-sectional area was determined in the left ventricular lateral-midfree wall, including epicardial and endocardial portions, in HE-stained sections [44]. Immunohistochemistry staining of cardiomyocytes with dystrophin antibody $(1: 200$, Proteintech Inc., Wuhan, China) was also performed to observe the change in cardiomyocyte morphology of rats. Paraffin sections of the myocardial infarct border and remote zone (apex of heart) were immunohistochemically stained with an endothelial marker CD31 antibody (1:500, Servicebio Inc., Wuhan, China) to show capillary and arteriolar density in the myocardial tissue [45].

2.12. Cell Experiments. Human pulmonary arterial endothelial cells (HPAECs) (ScienCell Research Laboratories, Carlsbad, CA, USA) were cultured in DMEM containing 10\% FBS, $1 \%$ penicillin and streptomycin, and $1 \%$ growth factor at $37^{\circ} \mathrm{C}$ in an incubator containing $95 \%$ air and $5 \% \mathrm{CO}_{2}$. Tumor necrosis factor- $\alpha$ (TNF- $\alpha)(10 \mu \mathrm{g} / \mathrm{mL})$ was added to DMEM for $24 \mathrm{~h}$ to stimulate cells to mimic the similar inflammatory responses produced in heart failure. Then, 
TABLE 1: BW, HW, infracted area, and baseline hemodynamics in a representative group of CHF and Sham rats after two weeks of ContshRNA or Salusin- $\beta$-shRNA application.

\begin{tabular}{|c|c|c|c|c|}
\hline & \multicolumn{2}{|c|}{ Sham } & \multicolumn{2}{|c|}{$\mathrm{CHF}$} \\
\hline & Cont & Salusin- $\beta$ & Cont & Salusin- $\beta$ \\
\hline BW (g) & $424 \pm 5.9$ & $408 \pm 21.1$ & $415 \pm 7.3$ & $418 \pm 21.6$ \\
\hline $\mathrm{HW}(\mathrm{g})$ & $1.3 \pm 0.1$ & $1.2 \pm 0.1$ & $1.9 \pm 0.0^{\dagger}$ & $1.8 \pm 0.1^{\dagger}$ \\
\hline HW/BW (g/kg) & $3.0 \pm 0.1$ & $2.9 \pm 0.1$ & $4.6 \pm 0.1^{\dagger}$ & $4.3 \pm 0.2^{\dagger}$ \\
\hline Infarct size (\% LV area) & 0 & 0 & $43.1 \pm 1.0^{\dagger}$ & $30.4 \pm 1.0^{* \dagger}$ \\
\hline SAP (mmHg) & $142.5 \pm 4.2$ & $139.8 \pm 3.5$ & $112.5 \pm 3.2^{\dagger}$ & $122.4 \pm 3.6^{* \dagger}$ \\
\hline DAP (mmHg) & $103.5 \pm 5.1$ & $102.5 \pm 6.7$ & $95.6 \pm 7.2$ & $86.7 \pm 6.2$ \\
\hline PP (mmHg) & $39.0 \pm 7.2$ & $37.2 \pm 6.9$ & $17.0 \pm 2.9^{\dagger}$ & $35.7 \pm 3.0^{*}$ \\
\hline MAP (mmHg) & $119.5 \pm 6.7$ & $116.2 \pm 6.4$ & $102.3 \pm 5.2^{\dagger}$ & $97.5 \pm 6.1^{\dagger}$ \\
\hline HR (beats/min) & $386.9 \pm 26.2$ & $335.9 \pm 20.6$ & $358.7 \pm 38.2$ & $375.9 \pm 26.1$ \\
\hline LVSP (mmHg) & $137.9 \pm 6.1$ & $129.7 \pm 7.3$ & $97.9 \pm 3.3^{\dagger}$ & $109.8 \pm 4.6^{* \dagger}$ \\
\hline LVEDP (mmHg) & $2.5 \pm 1.7$ & $1.9 \pm 1.4$ & $13.5 \pm 0.7^{\dagger}$ & $10.3 \pm 0.5^{* \dagger}$ \\
\hline LVDP (mmHg) & $135.3 \pm 6.7$ & $127.7 \pm 7.0$ & $84.5 \pm 5.2^{\dagger}$ & $99.5 \pm 4.5^{*^{\dagger}}$ \\
\hline $\mathrm{LV}+\mathrm{dP} / \mathrm{dt}_{\max }(\mathrm{mmHg} / \mathrm{sec})$ & $3669.8 \pm 396.0$ & $3725.9 \pm 423.0$ & $1981.7 \pm 133.3^{\dagger}$ & $3389.6 \pm 333.9^{*}$ \\
\hline
\end{tabular}

BW: body weight; HW: heart weight; SAP: systolic arterial pressure; DAP: diastolic arterial pressure; PP: pulse pressure; MAP: mean arterial pressure; HR: heart rate; LV: left ventricle; LVSP: left ventricle peak systolic pressure; LVEDP: left ventricle end-diastolic pressure; LVDP: left ventricle developed pressure; $\mathrm{LV}+\mathrm{dP} / \mathrm{dt}_{\max }:$ maximum of the first derivative of left ventricle pressure. Data are given as mean $\pm \mathrm{SE} .{ }^{*} P<0.05$ vs. Cont-shRNA. ${ }^{\dagger} P<0.05$ vs. Sham. $n=6$ for each group.

HPAECs were transfected with adenovirus-mediated shRNA against salusin $\beta$ or control shRNA $(\mathrm{MOI}=100)$ for $48 \mathrm{~h}$ to silence salusin- $\beta$ in vitro. Then, the eNOS activity, NO level, $\mathrm{NAD}(\mathrm{P}) \mathrm{H}$ oxidase activity, and ROS level of the cells were measured.

2.13. Chemicals. Salusin- $\beta$ was obtained from Bachem (Bubendorf, Switzerland). Prostaglandin F2 $\alpha$ (PGF $2 \alpha$ ), acetylcholine (ACh), $\mathrm{N}^{\prime}$-nitro-L-arginine-methyl ester hydrochloride (L-NAME), and TNF- $\alpha$ were purchased from Sigma Chemical Co. (St. Louis, MO, USA). The chemicals were dissolved in normal saline.

2.14. Statistical Analysis. Data are expressed as the mean $\pm \mathrm{S}$ .E. The Kolmogorov-Smirnov test and Shapiro-Wilk test were used to measure the normal distribution of values. Student's unpaired $t$-test was used for comparisons between two groups. One-way or two-way ANOVA was used, followed by the Bonferroni test for posthoc analysis when multiple comparisons were made. $P<0.05$ was considered statistically significant.

\section{Results}

3.1. Effects of Salusin- $\beta$ Knockdown on Anatomy and Hemodynamics. The body weight (BW), heart weight (HW), infarct area, and baseline hemodynamic arguments were measured after two weeks of cont-shRNA or salusin$\beta$-shRNA application in CHF and Sham rats. Although the BW was not significantly different between CHF and Sham rats, the $\mathrm{HW}$ and the $\mathrm{HW} / \mathrm{BW}$ were increased in CHF rats, which suggested the occurrence of myocardial hypertrophy. Knockdown of salusin- $\beta$ decreased the infarct size of the
$\mathrm{LV}$ in CHF rats. Compared with the Sham rats, the SAP, PP, LVSP, LVDP, and LV $+\mathrm{dP}^{\mathrm{d} t_{\max }}$ decreased, while LVEDP increased significantly in CHF rats, which was consistent with our previous study findings [46]. These abnormal hemodynamic parameters in CHF were improved by salusin$\beta$ knockdown (Table 1).

3.2. Effects of Salusin- $\beta$ Knockdown on Echocardiography. Compared to Sham rats, the LVEDD, LVESD, LV mass, and LV mass/BW were obviously increased, while EF, FS, and LVPWs were significantly decreased in CHF rats. More importantly, these abnormal parameters, except LV mass and LV mass/BW, of CHF rats were improved by salusin- $\beta$ knockdown (Table 2).

3.3. Effects of Salusin- $\beta$ Knockdown on Salusin- $\beta$ Levels in Plasma and Protein Expression in Arteries. The content of salusin- $\beta$ in the plasma (Figure $1(\mathrm{a})$ ) and salusin- $\beta$ protein expression in the CA, PA, and MA (Figure 1(b)) of CHF rats were significantly higher than those of Sham rats. After tail intravenous injection of adenoviral vectors encoding salu$\sin -\beta$ shRNA to knockdown salusin- $\beta$, the salusin- $\beta$ levels in the plasma and salusin- $\beta$ protein expression in arteries were decreased considerably in both CHF and Sham rats.

3.4. Effects of Salusin- $\beta$ Knockdown on Plasma Leptin and Visfatin Levels. Both the leptin (Figure 1(c)) and visfatin levels (Figure $1(\mathrm{~d})$ ) in plasma were increased in CHF rats compared with Sham rats and were restored by salusin- $\beta$ shRNA intervention in CHF rats.

3.5. Effects of Salusin- $\beta$ Knockdown on EndotheliumDependent Vascular Relaxation. ACh-induced dosedependent relaxations in CA, PA, and MA were attenuated 
TABLE 2: Echocardiographic data of the left ventricle in a representative group of Sham and CHF rats after two weeks of Cont-shRNA or salusin- $\beta$-shRNA application.

\begin{tabular}{|c|c|c|c|c|}
\hline & \multicolumn{2}{|c|}{ Sham } & \multicolumn{2}{|c|}{$\mathrm{CHF}$} \\
\hline & Cont & Salusin- $\beta$ & Cont & Salusin- $\beta$ \\
\hline LVEDD, $\mathrm{mm}$ & $7.12 \pm 0.23$ & $6.76 \pm 0.43$ & $11.36 \pm 0.21^{\dagger}$ & $9.24 \pm 0.28^{* \dagger}$ \\
\hline LVESD, mm & $4.65 \pm 0.13$ & $3.49 \pm 0.30$ & $9.27 \pm 0.40^{\dagger}$ & $7.86 \pm 0.25^{* \dagger}$ \\
\hline IVSd, mm & $1.79 \pm 0.05$ & $1.70 \pm 0.10$ & $1.28 \pm 0.13$ & $1.40 \pm 0.19$ \\
\hline IVSs, mm & $2.86 \pm 0.13$ & $2.93 \pm 0.14$ & $1.86 \pm 0.26$ & $1.76 \pm 0.26$ \\
\hline LVPWd, mm & $1.86 \pm 0.03$ & $1.97 \pm 0.12$ & $1.63 \pm 0.10$ & $2.02 \pm 0.07$ \\
\hline LVPWs, mm & $3.21 \pm 0.11$ & $3.08 \pm 0.11$ & $2.46 \pm 0.30^{\dagger}$ & $2.97 \pm 0.08^{*}$ \\
\hline FS, \% & $43.41 \pm 1.24$ & $48.54 \pm 1.90$ & $17.84 \pm 1.02^{\dagger}$ & $25.52 \pm 2.01^{* \dagger}$ \\
\hline $\mathrm{EF}, \%$ & $72.60 \pm 1.33$ & $78.59 \pm 1.83$ & $34.73 \pm 1.78^{\dagger}$ & $47.55 \pm 3.30^{* \dagger}$ \\
\hline LV mass (g) & $1.19 \pm 0.08$ & $1.03 \pm 0.17$ & $1.55 \pm 0.10^{\dagger}$ & $1.53 \pm 0.08^{\dagger}$ \\
\hline LV mass/BW (mg/g) & $2.81 \pm 0.33$ & $2.52 \pm 0.47$ & $3.73 \pm 0.47^{\dagger}$ & $3.66 \pm 0.32^{\dagger}$ \\
\hline
\end{tabular}

LVEDD: left ventricular end-diastolic diameter; LVESD: left ventricular end-systolic diameter; IVSd: interventricular septal thickness in diastole; IVSs: interventricular septal thickness in systole; LVPWd: left ventricular posterior wall thickness in diastole; LVPWs: left ventricular posterior wall thickness in systole; FS: fractional shortening; EF: ejection fraction; LV: left ventricular; BW: body weight. Values are mean \pm SE. ${ }^{*} P<0.05$ vs. Cont-shRNA. ${ }^{\dagger} P<0.05$ vs. Sham. $n=6$ for each group.

in CHF rats compared with Sham rats and were ameliorated significantly by silencing salusin- $\beta$. Silencing of salusin- $\beta$ had no significant effect on endothelium-dependent vascular relaxation in Sham rats (Figure 2).

3.6. Effects of L-NAME on Vascular Relaxation in Response to Salusin- $\beta$ Knockdown. Pretreatment with the NOS inhibitor L-NAME in CHF rats significantly inhibited the improved effects of salusin- $\beta$ knockdown on endothelium-dependent vascular relaxation (Figure 2).

3.7. Effects of Salusin- $\beta$ Knockdown on eNOS Activity and Protein Expression and NO Levels in Arteries. Compared with Sham rats, the p-eNOS protein expression (Figures 3(a) and 3(b)) of CA, PA, and MA in CHF rats was decreased, and the T-eNOS protein expression (Figures 3(a) and 3(c)) of $\mathrm{CA}$ and MA in CHF rats was also decreased. eNOS activity was evaluated by p-eNOS/T-eNOS (Figure 3(d)), which was also significantly decreased in these three arteries of $\mathrm{CHF}$ rats. These results indicated that both the eNOS amount and activity of arteries were decreased in CHF rats. Consistent with this, NO levels (Figure 3(e)) in these three arteries of $\mathrm{CHF}$ rats were also much lower than those of Sham rats. They were all redressed by salusin- $\beta$ knockdown. However, silencing salusin- $\beta$ had no significant effect on eNOS activity and protein expression or NO levels in arteries, except CA, of Sham rats (Figure 3).

3.8. Effects of Salusin- $\beta$ Knockdown on $N A D(P) H$ Oxidase Activity and ROS Levels in Arteries. In CHF rats, the $\mathrm{NAD}(\mathrm{P}) \mathrm{H}$ oxidase activity (Figure $4(\mathrm{a})$ ) and $\mathrm{NAD}(\mathrm{P}) \mathrm{H}$ oxidase subunit NOX-2 (Figures 4(b) and 4(c)) and NOX-4 (Figures 4(b) and 4(d)) protein expression of CA, PA, and MA were increased significantly. The level of ROS (Figure $4(\mathrm{e})$ ) in arteries in CHF rats was higher than that of Sham rats. They were all corrected by salusin- $\beta$ knockdown in $\mathrm{CHF}$ rats. However, silencing salusin- $\beta$ had no significant effect on NAD(P)H oxidase activity or NOX-2 and NOX-4 protein expression or ROS levels in the arteries of Sham rats (Figure 4).

3.9. Effects of L-NAME on NO and ROS Responses to Salusin$\beta$ Knockdown. The application of L-NAME to CHF rats significantly inhibited the elevating effects of salusin- $\beta$ knockdown on NO levels and the depressing effects on NAD $(\mathrm{P}) \mathrm{H}$ oxidase activity and ROS levels (Table 3 ).

3.10. Effects of Salusin- $\beta$ Knockdown on Vascular Remodeling. The lumen diameters of the CA, PA, and MA (Figures 5(a) and 5(c)) of CHF rats were reduced, while the media thickness (Figures 5(a) and 5(b)) and the ratio of media thickness to lumen diameter (Figure 5(d)) were increased compared with those of Sham rats, which indicated the occurrence of vascular remodeling. Silencing of salusin- $\beta$ in $\mathrm{CHF}$ rats increased the lumen diameter and decreased the media thickness and the ratio of media thickness to lumen diameter of CA, PA, and MA, suggesting that vascular remodeling was improved by salusin- $\beta$ knockdown (Figure 5).

3.11. Effects of Salusin- $\beta$ Knockdown on Left Ventricular Remodeling and Microvascular Density. Severe perivascular and myocardium fibrosis of sections of myocardium with Masson's stain (Figures 6(a) and 6(c)), cardiomyocyte hypertrophy with HE stain (Figures 6(b) and 6(d)), and increased cross-sectional area of cardiomyocytes (Figure 6(e)) of left ventricular were observed in CHF. Morphometric dystrophin staining of cardiomyocytes also showed the occurrence of cardiomyocyte hypertrophy in CHF rats (Figure 6(f)). They were all blunted by salusin- $\beta$ knockdown. Furthermore, the capillary and arteriolar density was increased significantly in the infarcted area after salusin- $\beta$ silencing in $\mathrm{CHF}$ 


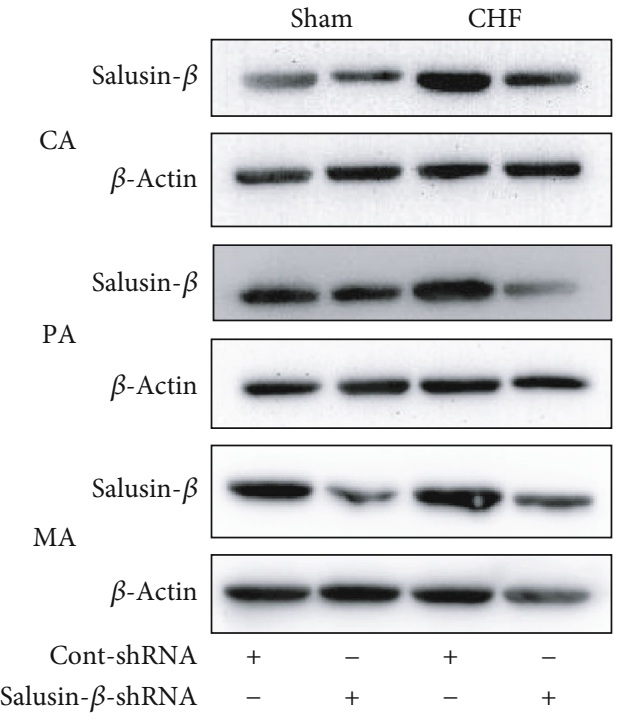

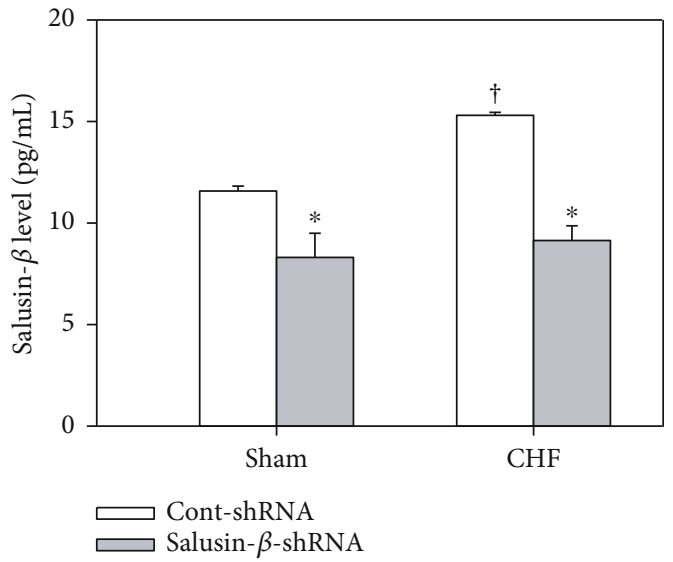

(a)

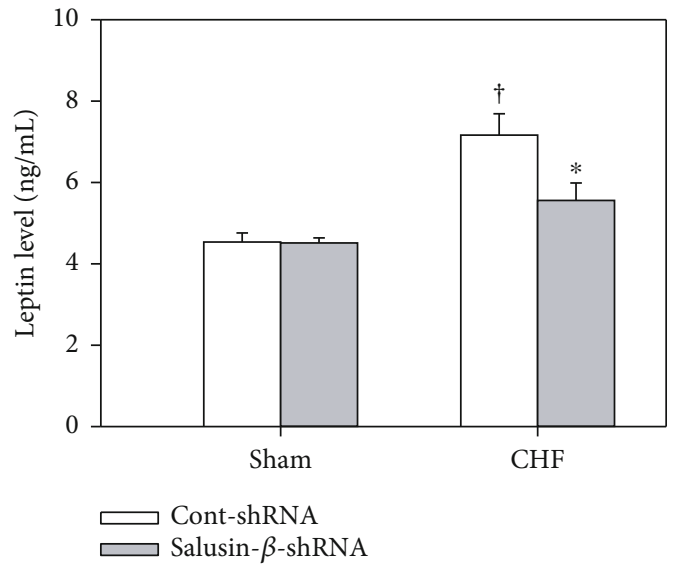

(c)

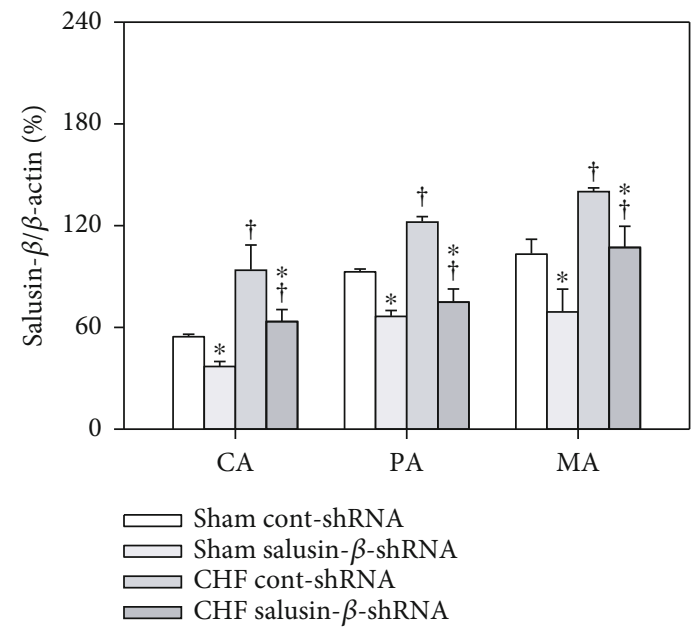

(b)

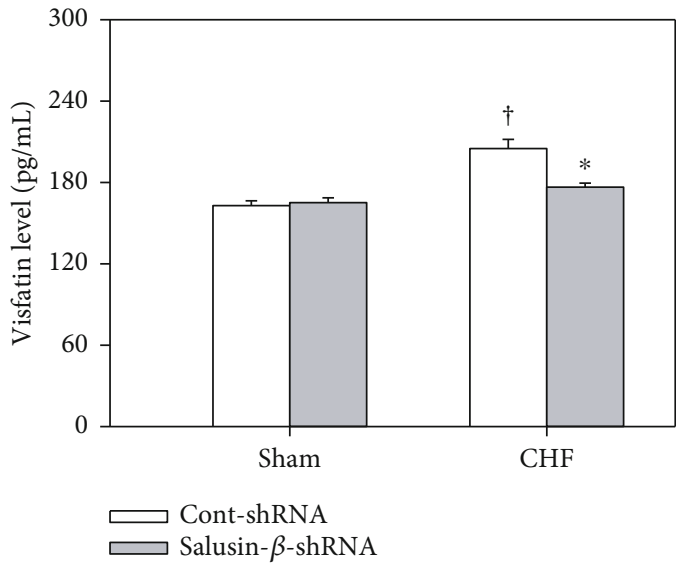

(d)

FIGURE 1: The salusin- $\beta$ level in plasma (a), salusin- $\beta$ protein expression of CA, PA, and MA (b), leptin (c), and visfatin levels (d) of plasma in Sham and CHF rats with salusin- $\beta$ knockdown. Values are mean \pm SE. ${ }^{*} P<0.05$ compared with Cont-shRNA, ${ }^{\dagger} P<0.05$ compared with Sham. $n=6$ for each group.

rats (Figure 6(g)), which might suggest the occurrence of neovascularization in the infarcted area of CHF rats after salusin- $\beta$ knockdown. However, there was no significant dif- ference in microvascular density in the noninfarcted area (apex of heart) (Figure 6(h)) between Sham and CHF rats treated with either Cont-shRNA or salusin- $\beta$-shRNA. 

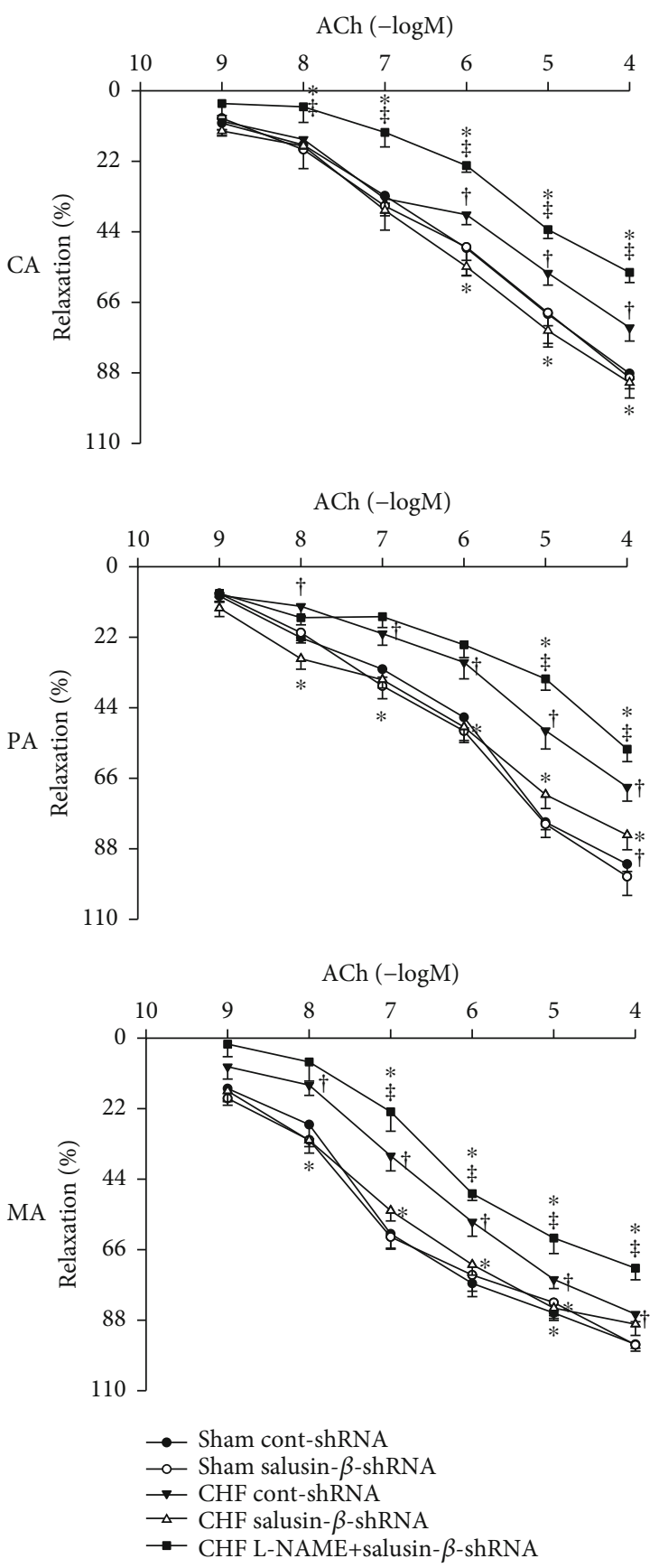

FIGURE 2: ACh-induced dose-dependent relaxation of CA, PA, and $\mathrm{MA}$ in Sham and $\mathrm{CHF}$ rats. Values are mean $\pm \mathrm{SE} .{ }^{*} P<0.05$ compared with Cont-shRNA, ${ }^{\dagger} P<0.05$ compared with Sham, ${ }^{\ddagger} P<0.05$ compared with CHF salusin- $\beta$-shRNA. $n=6$ for each group.

3.12. Effects of Salusin- $\beta$ Knockdown on NO and ROS of Cells. After the application of TNF- $\alpha$ to HPAECs, the eNOS activity (Figure $7(\mathrm{a})$ ) and NO level (Figure 7(b)) in the cells were decreased, while the activity of $\mathrm{NAD}(\mathrm{P}) \mathrm{H}$ oxidase (Figure 7(c)) and the level of ROS (Figure 7(d)) were increased, which was consistent with the situation that occurred in CHF. The changes induced by TNF- $\alpha$ were also reversed by silencing salusin- $\beta$ gene expression in cells.
3.13. Effects of Salusin- $\beta$ Knockdown on $N A D(P) H$ Oxidase Activity and ROS and NO Levels in Cardiac Tissues. We found that there was no significant difference of salusin- $\beta$ protein expression in cardiac tissues between Sham and CHF rats. Compared with Sham rats, the $\mathrm{NAD}(\mathrm{P}) \mathrm{H}$ oxidase activity and ROS level in cardiac tissues in CHF rats were increased, and NO levels were decreased. However, they were not influenced by tail intravenous injection of salusin- $\beta$ shRNA (Supplemental Figure S1). These results indicated that salusin- $\beta$ in cardiomyocytes does not play a direct role in regulating the NO and ROS signaling pathways in rats, which excluded the direct effect of salusin- $\beta$ knockdown on cardiomyocytes.

3.14. The Salusin- $\alpha$ Level in Sham and CHF Rats. There were no significant differences in the plasma level of salusin- $\alpha$ or its protein expression in the three arteries, MA, CA, and PA, or cardiac tissues between Sham and CHF rats (Supplemental Figure S2). We speculated that salusin- $\alpha$ might not be involved in the pathogenesis of CHF.

\section{Discussion}

Endothelium-dependent diastolic dysfunction is closely related to the occurrence and development of $\mathrm{CHF}$ and could trigger deteriorating events, such as cardiovascular remodeling, in CHF patients. The CA, PA, and MA are three essential arteries related to endothelial dysfunction in CHF. The major new findings of the present study were (1) The levels of salu$\sin -\beta$, leptin, and visfatin in plasma and salusin- $\beta$ protein expressions of CA, PA, and MA of CHF were much higher than that of Sham rats, which were decreased significantly by salusin- $\beta$ knockdown; (2) endothelium-dependent vascular relaxation was attenuated in CHF which was improved by salusin- $\beta$ knockdown; (3) the eNOS activity and protein expressions as well as NO level in the three arteries of CHF were lower than those of Sham rats, while $\mathrm{NAD}(\mathrm{P}) \mathrm{H}$ oxidase activity, NOX-2 and NOX-4 protein expressions, and ROS level of arteries were higher than those of the Sham rats. After salusin- $\beta$ knockdown, these abnormalities were substantially improved; (4) the improved effects of salusin- $\beta$ knockdown on ACh-induced vascular relaxation, NO level, NAD $(\mathrm{P}) \mathrm{H}$ oxidase activity, and ROS level of arteries of CHF were inhibited by L-NAME pretreatment; (5) the interference of salusin- $\beta$ gene expression in CHF rats improved cardiac function, vascular remodeling, and left ventricular remodeling and promotes the angiogenesis in infarct zone of heart; (6) silencing of the salusin- $\beta$ gene expression also reversed the depressed eNOS activity and NO level as well as the increased $\mathrm{NAD}(\mathrm{P}) \mathrm{H}$ oxidase activity and the ROS level of HPAECs stimulated by TNF- $\alpha$. These results indicated that salusin- $\beta$ is closely related to endothelial dysfunction and vascular and ventricular remodeling in chronic heart failure. Knockdown of salusin- $\beta$ contributes to the improvement of endothelial dysfunction, cardiac function, and cardiovascular remodeling in CHF by inhibiting vascular $\mathrm{NAD}(\mathrm{P}) \mathrm{H}$ oxidase-derived ROS generation, activating eNOS and increasing NO production. 

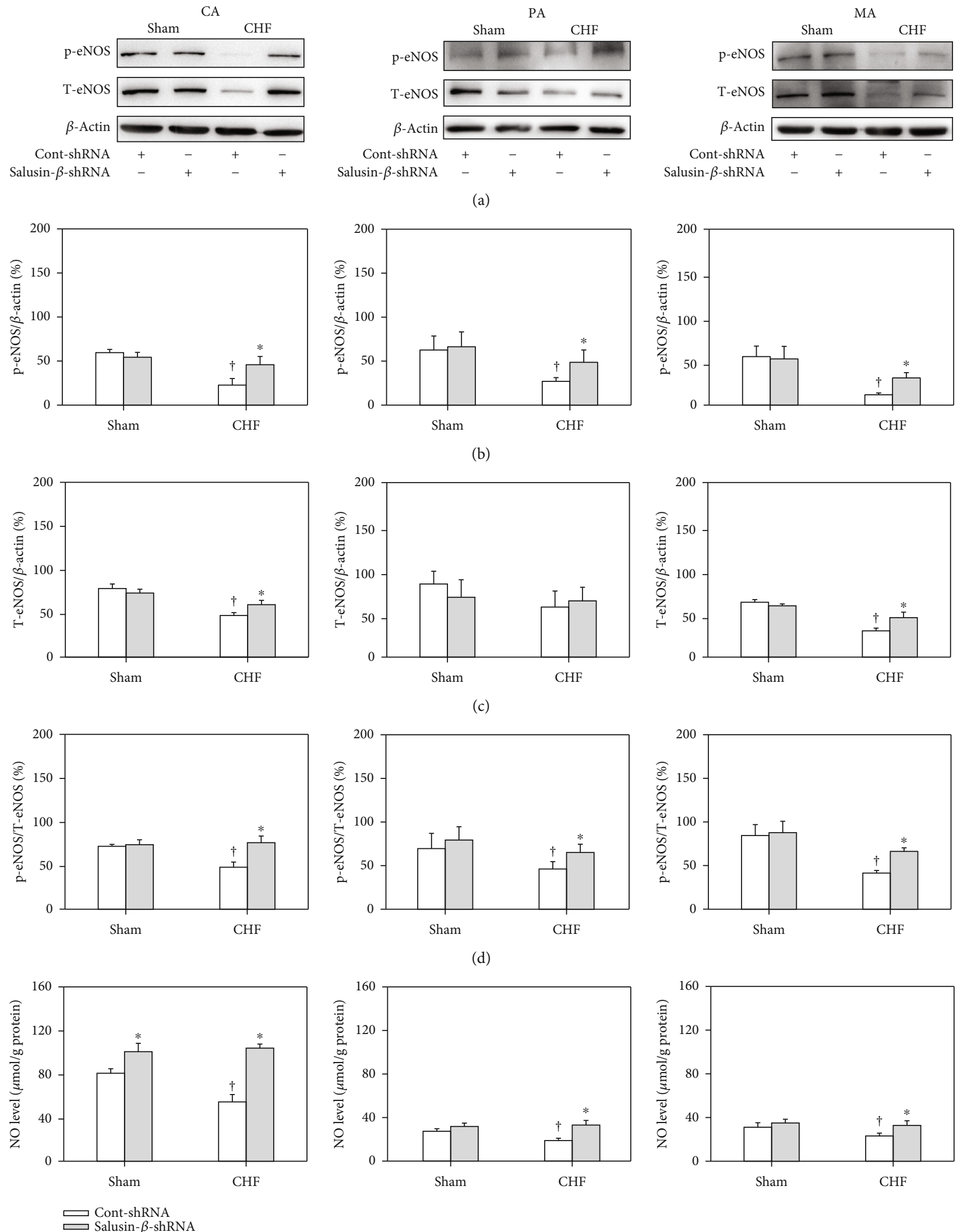

(e)

FIgure 3: The protein expression of p-eNOS (a, b), T-eNOS (a, c), and p-eNOS/T-eNOS (d), as well as NO level (e) of CA, PA, and MA in Sham and CHF rats. Values are mean \pm SE. ${ }^{*} P<0.05$ compared with Cont-shRNA, ${ }^{\dagger} P<0.05$ compared with Sham. $n=6$ for each group. 

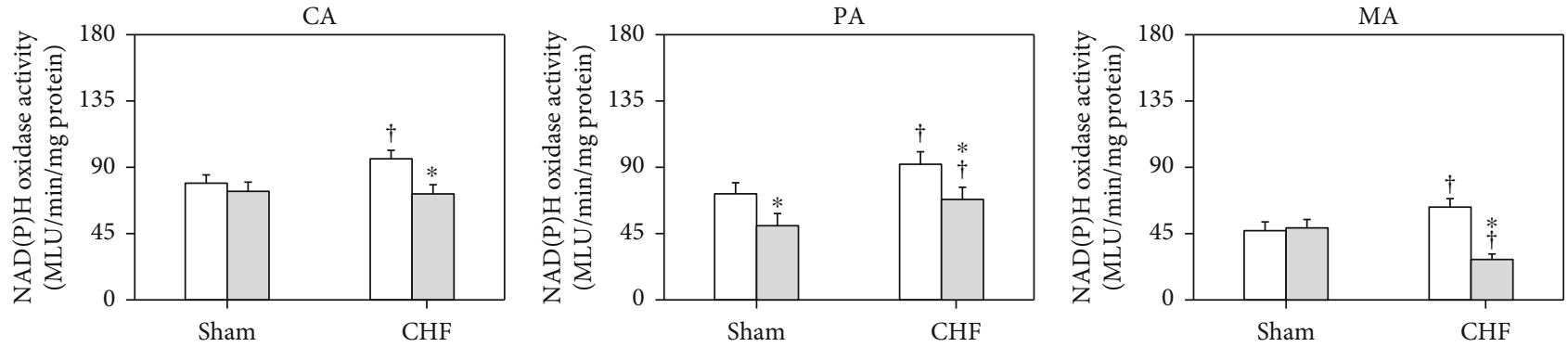

(a)
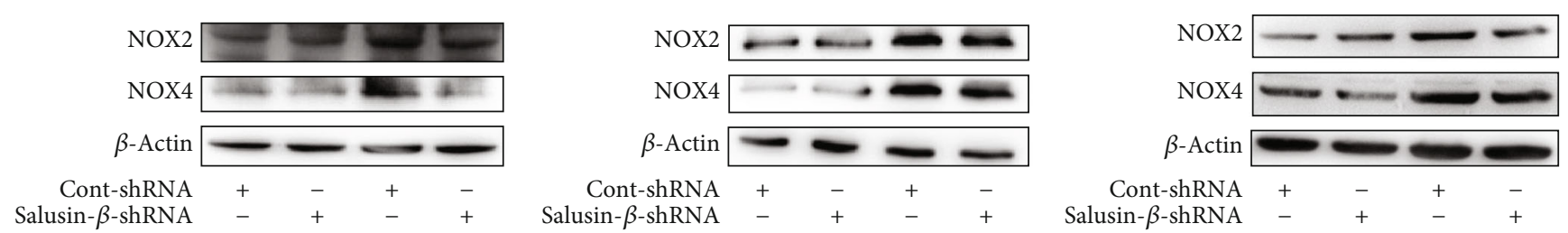

(b)
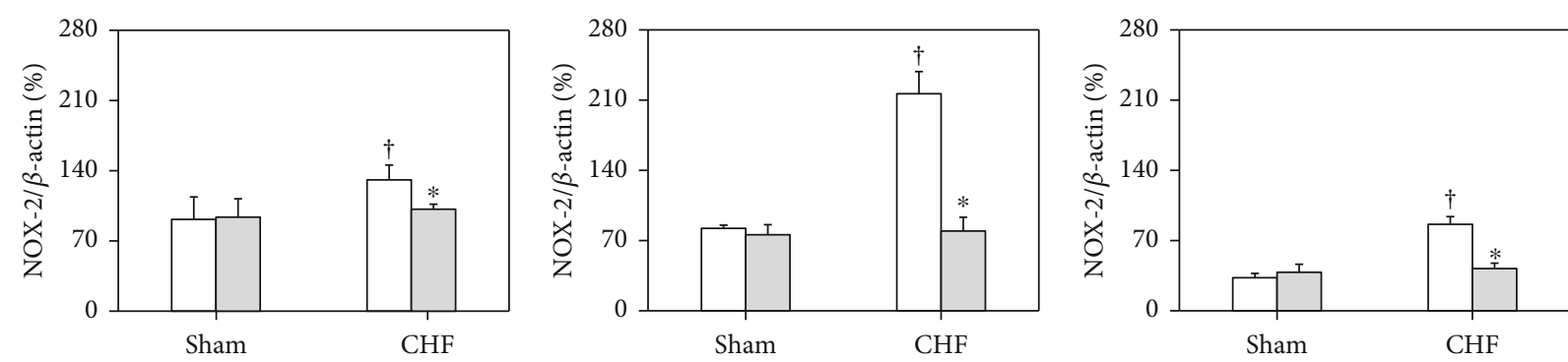

(c)
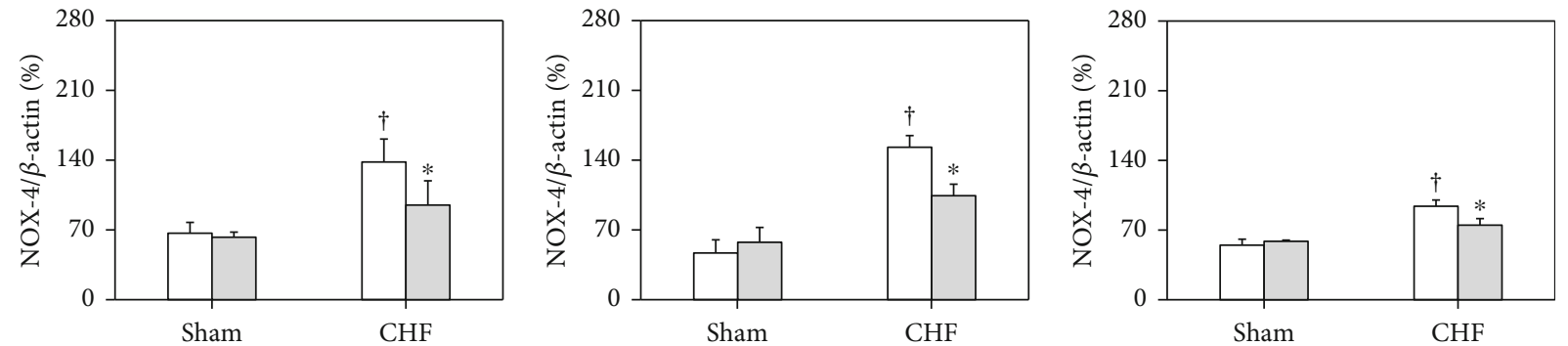

(d)
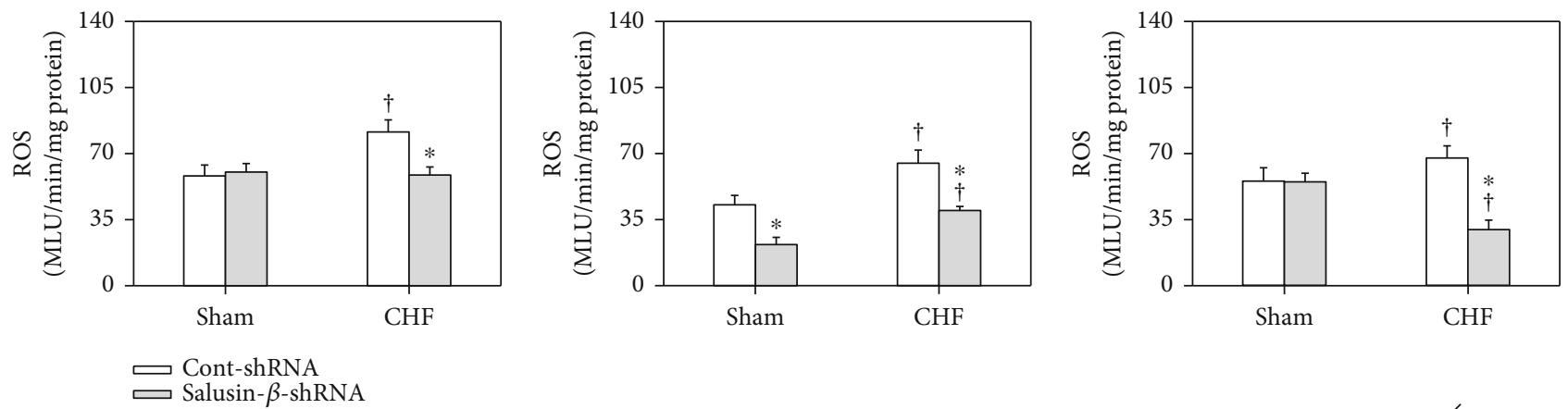

(e)

Figure 4: NAD(P)H oxidase activity (a), NOX-2 (b, c), and NOX-4 protein expression (b, d), as well as ROS levels (e), of CA, PA, and MA in Sham and CHF rats. Values are mean \pm SE. ${ }^{*} P<0.05$ compared with Cont-shRNA, ${ }^{\dagger} P<0.05$ compared with Sham. $n=6$ for each group. 
TABLE 3: Influence of gavage treatment with saline and L-NAME on the NO level, NAD(P)H oxidase activity, and ROS level of CA, PA, and MA in CHF rats with Cont-shRNA or salusin- $\beta$-shRNA.

\begin{tabular}{|c|c|c|c|c|}
\hline & \multicolumn{2}{|c|}{ Saline } & \multicolumn{2}{|c|}{ L-NAME } \\
\hline & Cont-shRNA & Salusin- $\beta$-shRNA & Cont-shRNA & Salusin- $\beta$-shRNA \\
\hline \multicolumn{5}{|l|}{$\overline{C A}$} \\
\hline NO level ( $\mu \mathrm{mol} / \mathrm{g}$ protein $)$ & $54.6 \pm 3.7$ & $98.4 \pm 5.4^{*}$ & $26.6 \pm 6.3^{\dagger}$ & $39.0 \pm 3.9^{\dagger}$ \\
\hline $\mathrm{NAD}(\mathrm{P}) \mathrm{H}$ oxidase activity (MLU/min/mg protein) & $96.1 \pm 5.6$ & $74.3 \pm 2.3^{*}$ & $151.1 \pm 13.6^{\dagger}$ & $165.8 \pm 1.8^{\dagger}$ \\
\hline ROS level (MLU/min/mg protein) & $81.7 \pm 4.5$ & $63.1 \pm 0.8^{*}$ & $130.3 \pm 9.7^{\dagger}$ & $142.4 \pm 2.5^{\dagger}$ \\
\hline \multicolumn{5}{|l|}{$P A$} \\
\hline NO level ( $\mu \mathrm{mol} / \mathrm{g}$ protein $)$ & $19.1 \pm 2.2$ & $30.3 \pm 4.8^{*}$ & $11.9 \pm 1.0^{\dagger}$ & $13.2 \pm 1.9^{\dagger}$ \\
\hline $\mathrm{NAD}(\mathrm{P}) \mathrm{H}$ oxidase activity (MLU/min/mg protein) & $90.3 \pm 4.2$ & $63.0 \pm 6.1^{*}$ & $130.3 \pm 7.7^{\dagger}$ & $117.3 \pm 5.5^{\dagger}$ \\
\hline ROS level (MLU/min/mg protein) & $65.1 \pm 5.6$ & $46.9 \pm 4.3^{*}$ & $96 \pm 6.7^{\dagger}$ & $103.6 \pm 6.0^{\dagger}$ \\
\hline \multicolumn{5}{|l|}{$M A$} \\
\hline NO level ( $\mu \mathrm{mol} / \mathrm{g}$ protein $)$ & $23.3 \pm 2.5$ & $33.5 \pm 3.3^{*}$ & $10.1 \pm 0.7^{\dagger}$ & $11.9 \pm 1.6^{\dagger}$ \\
\hline $\mathrm{NAD}(\mathrm{P}) \mathrm{H}$ oxidase activity (MLU/min/mg protein) & $63.3 \pm 5.7$ & $24.1 \pm 5.9^{*}$ & $103.3 \pm 6.8^{\dagger}$ & $98.0 \pm 3.5^{\dagger}$ \\
\hline ROS level (MLU/min/mg protein) & $67.6 \pm 6.4$ & $21.0 \pm 4.7^{*}$ & $121.7 \pm 7.4^{\dagger}$ & $101.4 \pm 6.1^{\dagger}$ \\
\hline
\end{tabular}

Values are expressed as mean \pm SE. ${ }^{*} P<0.05$ vs. Cont-shRNA, ${ }^{\dagger} P<0.05$ vs. saline. $n=6$ for each group.

Salusins are vasoactive peptides, including salusin- $\alpha$ (28 amino acids) and salusin- $\beta$ (20 amino acids) [18]. Salusin- $\beta$ is more closely related to cardiovascular diseases than salu$\sin -\alpha[32,47]$. Salusin- $\beta$ is expressed in the hypothalamus, posterior pituitary gland, gastrointestinal tract, immune system, endocrine system, and peripheral vascular tissue, and it has rich expression in VECs and VSMCs [48-50]. The plasma salusin- $\beta$ levels in patients with diabetes mellitus [47], coronary artery disease $[51,52]$, and hypertension [36, 53] are distinctly higher than those in healthy controls. It has been reported that salusin- $\beta$ regulates blood pressure [27], activates sympathetic outflow [28], and promotes the proliferation, migration, and foam cell formation of VSMCs [29-31]. More importantly, salusin- $\beta$ is closely related to vascular endothelial function $[29,32]$. Salusin- $\beta$ causes endothelial injury and dysfunction in diabetes mellitus $[47,54,55]$ and promotes the inflammatory response of human umbilical vein endothelial cells through NF- $\kappa \mathrm{B}$ signaling $[47,56]$. However, whether the salusin- $\beta$ level in myocardial infarction-induced CHF is also increased and whether salu$\sin -\beta$ is involved in endothelial dysfunction and impaired cardiovascular function in $\mathrm{CHF}$ are still unknown. The present study found that both the plasma salusin- $\beta$ level and its protein expressions in the $\mathrm{CA}, \mathrm{PA}$, and $\mathrm{MA}$ of $\mathrm{CHF}$ rats were much higher than those of the Sham rats, which indicated that the activity of salusin- $\beta$ in $\mathrm{CHF}$ was increased. However, there were no significant differences in the salusin- $\alpha$ plasma level and its protein expressions in MA, CA, and PA and cardiac tissues between Sham and CHF rats, which suggested that salusin- $\alpha$ might not be involved in the pathogenesis of CHF.

It has been reported that plasma leptin and visfatin levels were increased in patients with myocardial infarction or other cardiovascular diseases [57, 58]. High levels of leptin increase oxidative stress in endothelial cells, reduce vasodilatation, and contribute to obesity-related hypertension [59]. Visfatin causes vascular endothelial dysfunction, inhibits the production of $\mathrm{NO}$ and vasodilatation, and promotes the proliferation of vascular smooth muscle cells [60]. Leptin and visfatin have been proposed as clinical markers of atherosclerosis, endothelial dysfunction, and vascular injury in cardiovascular disease. In this study, the leptin and visfatin levels in plasma were increased, while ACh-induced endothelium-dependent vascular relaxation was significantly attenuated in CHF, which suggested the occurrence of endothelial dysfunction in CHF rats. Salusin- $\beta$ knockdown by shRNA improved endothelium-dependent vascular relaxation and decreased the plasma leptin and visfatin levels in $\mathrm{CHF}$. These results indicated that salusin- $\beta$ is a critical regulator of endothelial function in $\mathrm{CHF}$, and the elevated activity of salusin- $\beta$ in the circulatory system in CHF might be an important cause of endothelial dysfunction in CHF.

It has been reported that salusin- $\beta$ stimulates the production of $\mathrm{NAD}(\mathrm{P}) \mathrm{H}$ oxidase-derived ROS in human umbilical vein endothelial cells [61-64]. Through the oxidative stress-related signaling pathway, salusin- $\beta$ stimulates the migration of VSMCs and intimal hyperplasia after vascular injury $[47,65]$. Salusin- $\beta$ promotes the formation of foam cells and monocyte adhesion in atherosclerosis by stimulating the production of $\operatorname{ROS}[30,31]$. Salusin- $\beta$ enhances oxidative stress and inflammation in diabetic cardiomyopathy, and knockdown of salusin- $\beta$ improves cardiac dysfunction and decreases oxidative stress and inflammation in diabetic cardiomyopathy [47]. In this study, it was found that both $\mathrm{NAD}(\mathrm{P}) \mathrm{H}$ oxidase activity and the protein expression of its subunits NOX-2 and NOX-4 in the CA, PA, and MA of $\mathrm{CHF}$ rats were increased. In addition, the ROS levels in the arteries of CHF rats were much higher than those of Sham rats. Silencing salusin- $\beta$ decreased the elevated $\mathrm{NAD}(\mathrm{P}) \mathrm{H}$ oxidase activity, NOX-2 and NOX-4 protein expression, and ROS levels in the arteries of CHF rats, which suggested that the activation of $\mathrm{NAD}(\mathrm{P}) \mathrm{H}$ oxidase and elevated ROS production played important roles in mediating the effects of salusin- $\beta$. In addition, we also found that the eNOS 


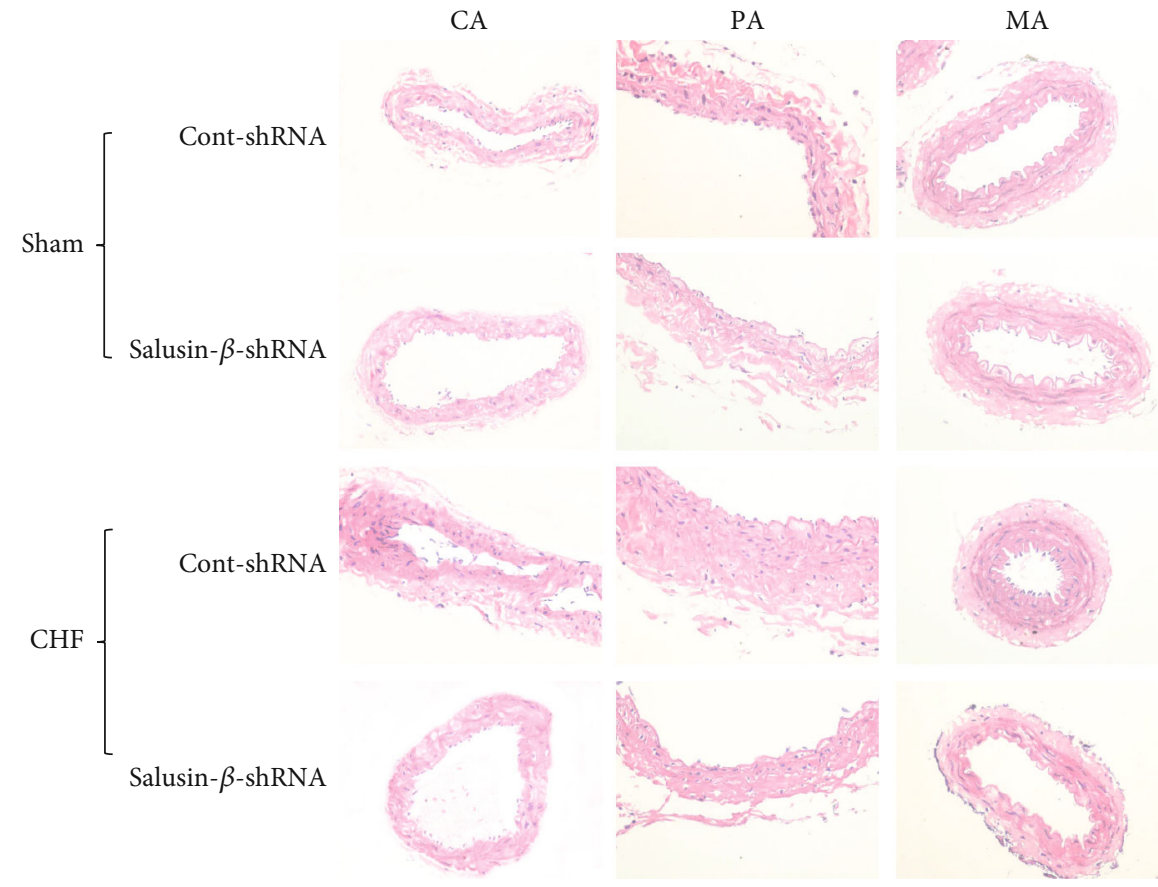

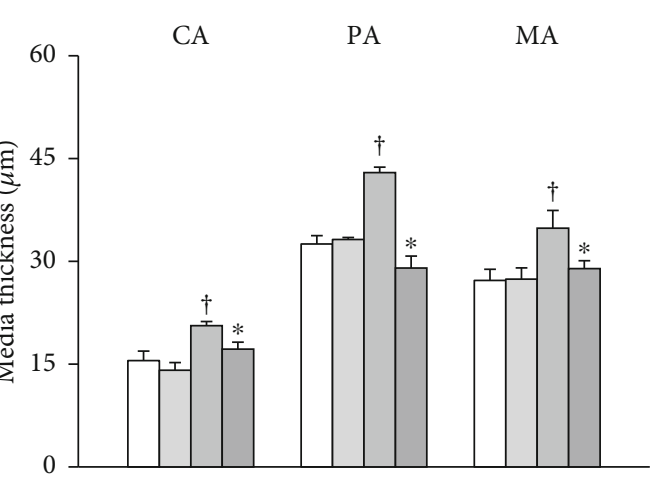

(b)

(a)

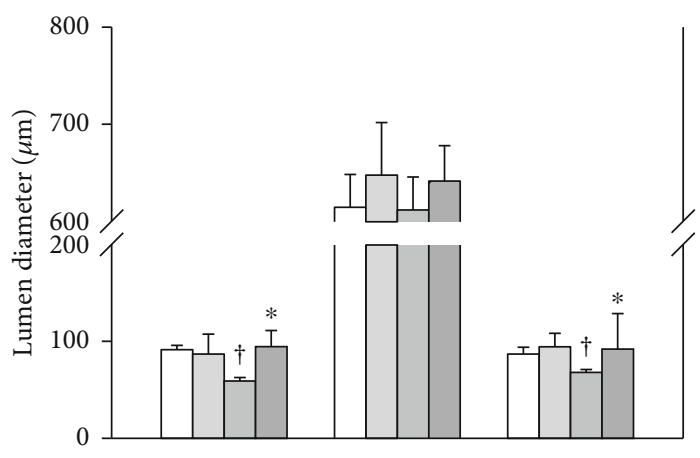

(c)

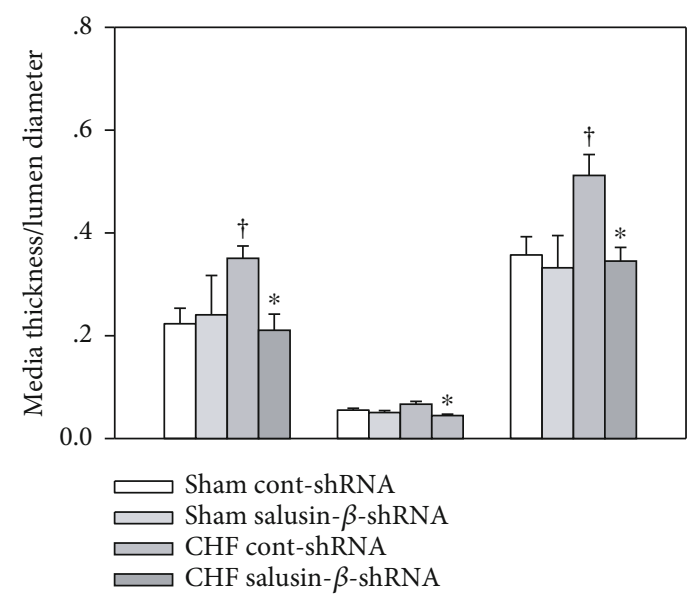

(d)

Figure 5: The media thickness (a, b), lumen diameter (a, c), and media thickness/lumen diameter (d) of CA, PA, and MA in Sham and CHF rats. Values are mean \pm SE. ${ }^{*} P<0.05$ compared with Cont-shRNA, ${ }^{\dagger} P<0.05$ compared with Sham. $n=6$ for each group. 


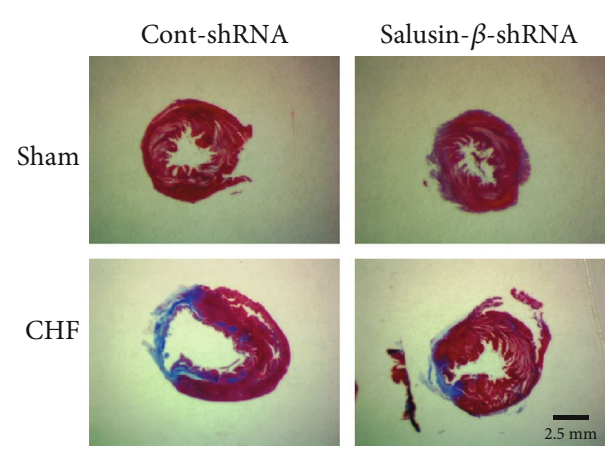

(a)

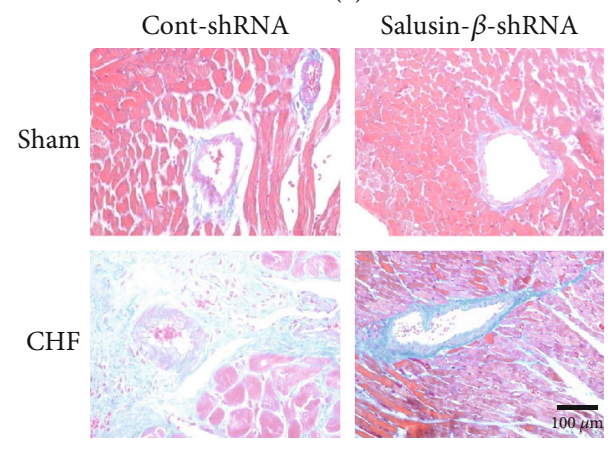

(c)

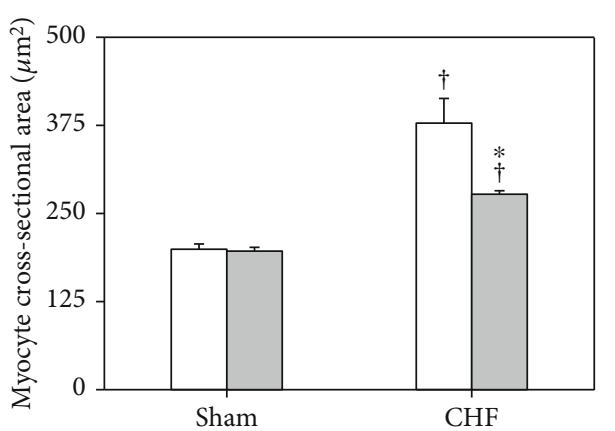

Cont-shRNA

$\longleftarrow$ Salusin- $\beta$-shRNA

(e)

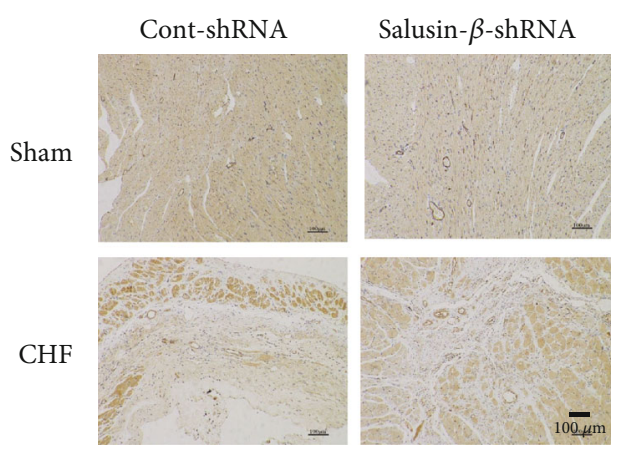

(g)

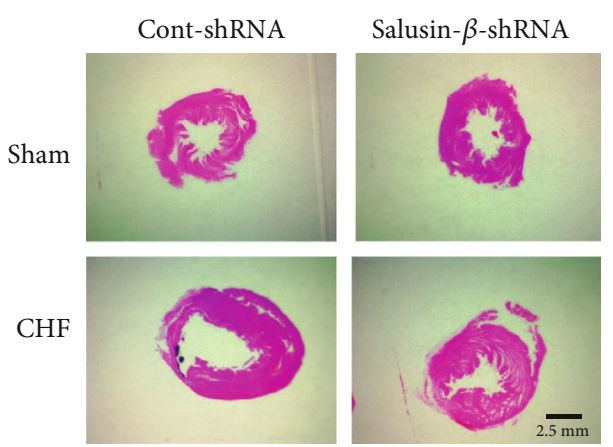

(b)

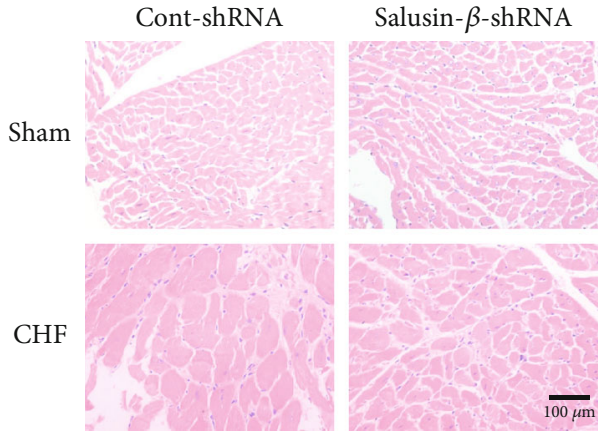

(d)

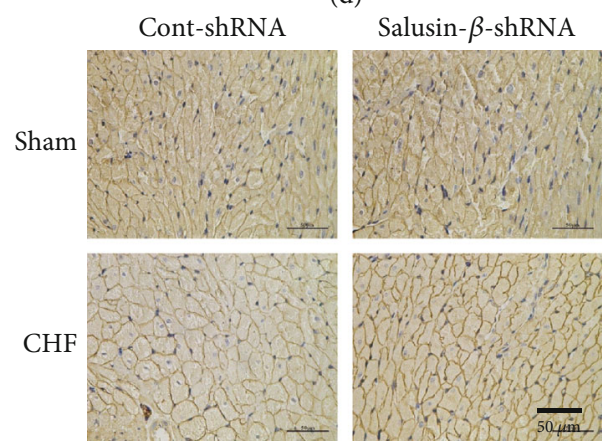

(f)

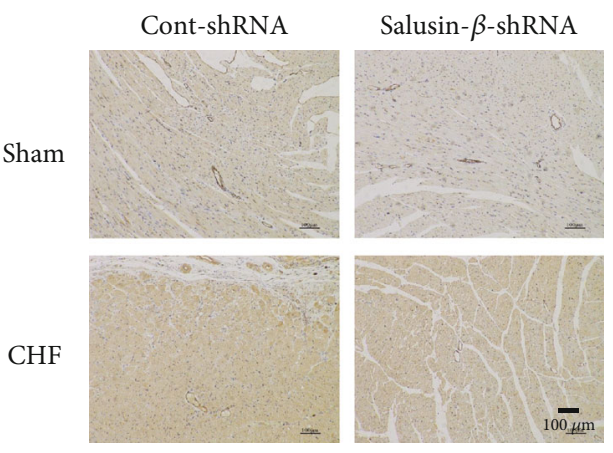

(h)

FIGURE 6: Effects of salusin- $\beta$ knockdown on left ventricular remodeling and microvascular density. Sections of myocardium with Masson's stain under low- (a) and high-power microscope (c) showing fibrosis. Sections of myocardium with HE staining under low- (b) and highpower microscopy (d) and dystrophin staining (f) showing the size of cardiomyocytes. Bar graph showing the quantitative analysis of the cross-sectional area of cardiomyocytes (e). Sections of myocardial infarct border (g) and remote zone (apex of heart) (h) with endothelial marker CD31 immunohistochemistry staining showing the microvascular density. Values are mean \pm SE. ${ }^{*} P<0.05$ compared with ContshRNA, ${ }^{\dagger} P<0.05$ compared with Sham. $n=6$ for each group. 


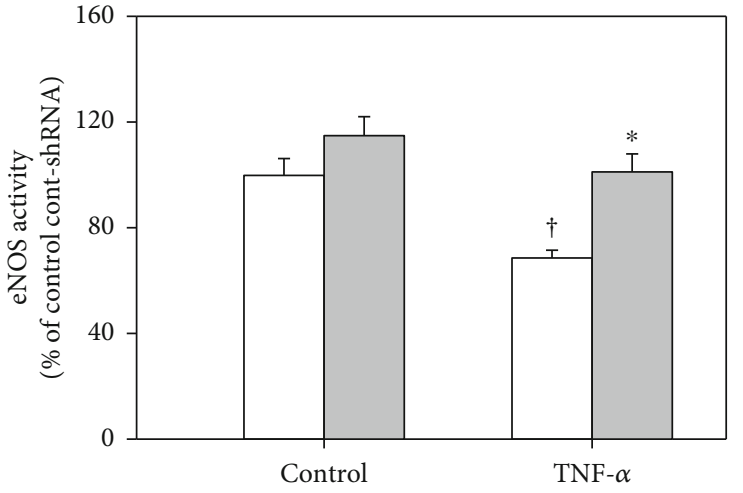

(a)

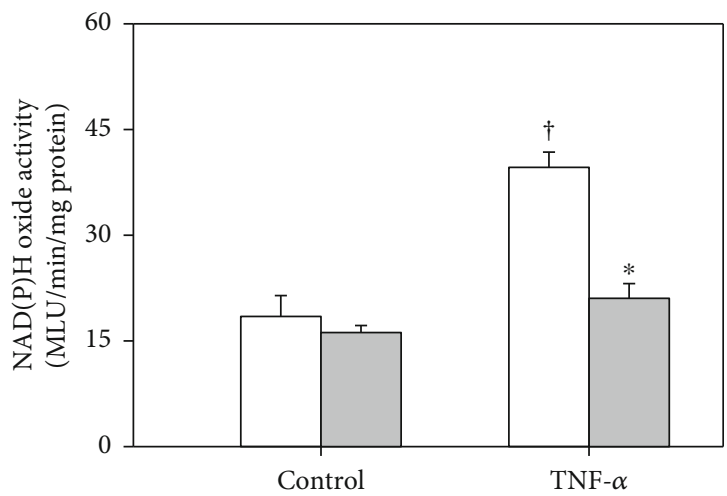

(c)

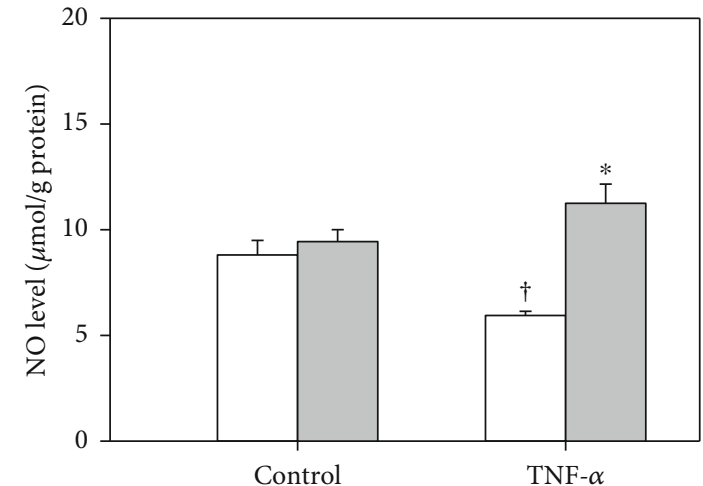

(b)

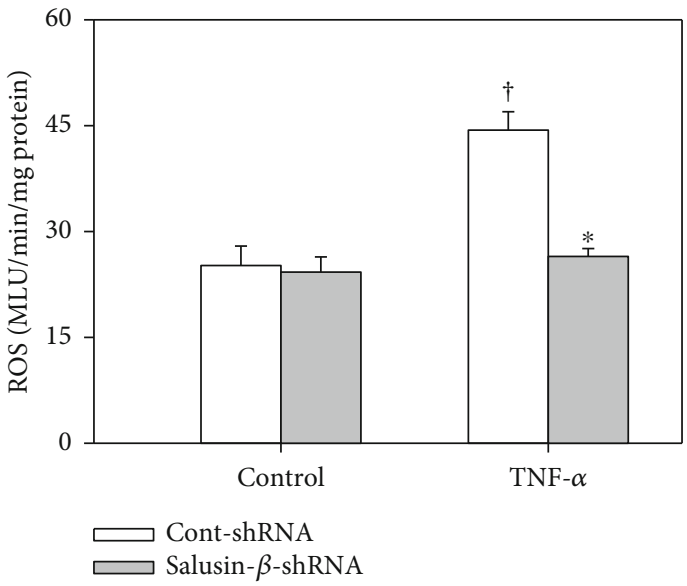

(d)

Figure 7: The effects of salusin- $\beta$ knockdown on eNOS activity (a), NO levels (b), NAD(P)H oxidase activity (c), and ROS levels (d) in HPAECs stimulated by TNF- $\alpha(10 \mathrm{ng} / \mathrm{mL})$. Values are mean \pm SE. ${ }^{*} P<0.05$ compared with Cont-shRNA, ${ }^{\dagger} P<0.05$ compared with control. $n=6$ for each group.

activity and protein expression and NO level in the three arteries of CHF rats were lower than those of Sham rats and were substantially improved by knockdown of salusin$\beta$. The effects of salusin- $\beta$ knockdown on ACh-induced vascular relaxation, $\mathrm{NO}$ levels, $\mathrm{NAD}(\mathrm{P}) \mathrm{H}$ oxidase activity, and ROS levels in CHF arteries were markedly inhibited by pretreatment with the NOS inhibitor L-NAME. Although the relationship between salusin- $\beta$ and NO is rarely reported at present, the above results suggested that lowering salusin- $\beta$ levels in circulation alleviated oxidative stress and improved damaged eNOS-NO production in CHF, which might be the major reason for the improvement of endothelial dysfunction by silencing salusin- $\beta$ expression.

$\mathrm{CHF}$ is a chronic inflammatory response, and TNF- $\alpha$ plays an important role in its pathogenesis [66]. Studies have found that the levels of TNF- $\alpha$ in the peripheral circulation or heart tissues of patients with CHF are significantly increased $[67,68]$. In the present study, we used TNF- $\alpha$ to stimulate HPAECs to simulate the injury of endothelial cells suffering from chronic heart failure and found that the eNOS activity and NO levels of the cells were decreased, while $\mathrm{NAD}(\mathrm{P}) \mathrm{H}$ oxidase activity and ROS levels were increased, which were also reversed by cell transfection with salusin- $\beta$ shRNA.
Therefore, our in vitro cell experiments again verified the results found in animal experiments.

In this study, echocardiography showed that the EF and FS were markedly decreased, while the LVEDD, LVESD, LV mass, and LV mass/BW were obviously increased in CHF rats, suggesting the significant reduction of cardiac function and the occurrence of left ventricular compensatory myocardial hypertrophy in CHF rats. Masson's stain, HE staining, and dystrophin staining further revealed severe perivascular and myocardial fibrosis and cardiomyocyte hypertrophy in the LV myocardium of CHF. In addition, the lumen diameter of the $\mathrm{CA}, \mathrm{PA}$, and $\mathrm{MA}$ in $\mathrm{CHF}$ decreased, while the media thickness and media thickness/lumen diameter were significantly increased, suggesting the occurrence of vascular remodeling in CHF. The interference of salusin- $\beta$ gene expression in CHF rats improved cardiac function, vascular remodeling, and left ventricular remodeling and simultaneously induced neovascularization in the infarcted region of CHF rats, which might be the important reason for the decrease in the infarcted area. The mechanisms of these improvements in CHF are still not clear, but some studies have indicated that NO released from endothelial cells might be an inhibitor of vascular remodeling [69, 
70]. Therefore, we speculated that the improvement in vascular remodeling might be due to the improvement in endothelial function and the increase in eNOS-NO production in arteries induced by salusin- $\beta$ silencing. Then, improved vascular relaxation of CA in CHF increases the blood supply to the heart and relieves myocardial ischemia; improved MA relaxation decreases total peripheral resistance and, more importantly, decreases cardiac afterload, which all contribute to the subsequent improvement of left ventricular remodeling and cardiac function. In addition, improved PA relaxation in CHF decreased pulmonary vascular resistance and the incidence of pulmonary hypertension due to left heart disease.

In addition, we found that there were no significant differences in salusin- $\beta$ protein expression in cardiac tissues between Sham and CHF rats. Compared with Sham rats, the $\mathrm{NAD}(\mathrm{P}) \mathrm{H}$ oxidase activity and ROS level in cardiac tissues in CHF rats were increased, and NO level were decreased, which suggested the increased oxidative stress and impaired NO bioavailability also occurred in hearts of CHF rats. However, NAD(P)H activity, ROS, and NO levels were not influenced by tail intravenous injection of salusin$\beta$ shRNA. These results indicated that salusin- $\beta$ in cardiomyocytes might not play direct roles in regulating the NO and ROS signaling pathways in CHF rats, which excluded the direct effect of salusin- $\beta$ knockdown on cardiomyocytes.

In conclusion, the present study indicates that salusin$\beta$ in the circulatory system is closely related to endothelial dysfunction, cardiovascular remodeling, and cardiac dysfunction in CHF. Silencing salusin- $\beta$ contributes to the improvement of endothelial function, cardiac function, and cardiovascular remodeling in CHF by inhibiting $\mathrm{NAD}(\mathrm{P}) \mathrm{H}$ oxidase-derived ROS generation and activating eNOS and NO production, which provides a new strategy and target for the treatment of chronic heart failure in the future.

\section{Data Availability}

The data that support the findings of this study are available from the corresponding author upon reasonable request.

\section{Conflicts of Interest}

No competing financial interests exist.

\section{Authors' Contributions}

All authors contributed to the work in this paper. Y.H. conceived and designed the experiments. Y.X., Y.P., X.X.W., and A.D.C. performed the experiments and collected data. Y.X., X.Y.T., and X.X.L. analyzed the data. Y.H. wrote the manuscript.

\section{Acknowledgments}

This work was supported by the National Natural Science Foundation of China (81470538 and 31571168) and Qing Lan Project of Jiangsu Province of China.

\section{Supplementary Materials}

Supplemental figures associated with this article can be found in the Supplemental file. (Supplementary Materials)

\section{References}

[1] S. A. Dick and S. Epelman, "Chronic heart failure and inflammation: what do we really know?," Circulation Research, vol. 119, no. 1, pp. 159-176, 2016.

[2] C. Franssen, S. Chen, A. Unger et al., "Myocardial microvascular inflammatory endothelial activation in heart failure with preserved ejection fraction," JACC: Heart Failure, vol. 4, no. 4, pp. 312-324, 2016.

[3] K. Swedberg, "Importance of neuroendocrine activation in chronic heart failure. Impact on treatment strategies," European Journal of Heart Failure, vol. 2, no. 3, pp. 229-233, 2000.

[4] C. N. Marti, M. Gheorghiade, A. P. Kalogeropoulos, V. V. Georgiopoulou, A. A. Quyyumi, and J. Butler, "Endothelial dysfunction, arterial stiffness, and heart failure," Journal of the American College of Cardiology, vol. 60, no. 16, pp. 14551469, 2012.

[5] M. S. Hulshoff, X. Xu, G. Krenning, and E. M. Zeisberg, "Epigenetic regulation of endothelial-to-mesenchymal transition in chronic heart disease," Arteriosclerosis, Thrombosis, and Vascular Biology, vol. 38, no. 9, pp. 1986-1996, 2018.

[6] A. Daiber, N. Xia, S. Steven et al., "New therapeutic implications of endothelial nitric oxide synthase (eNOS) function/dysfunction in cardiovascular disease," International Journal of Molecular Sciences, vol. 20, no. 1, 2019.

[7] S. Godo and H. Shimokawa, "Endothelial functions," Arteriosclerosis, Thrombosis, and Vascular Biology, vol. 37, no. 9, pp. e108-e114, 2017.

[8] M. A. Incalza, R. D'Oria, A. Natalicchio, S. Perrini, L. Laviola, and F. Giorgino, "Oxidative stress and reactive oxygen species in endothelial dysfunction associated with cardiovascular and metabolic diseases," Vascular Pharmacology, vol. 100, pp. 119, 2018.

[9] K. Ghimire, H. M. Altmann, A. C. Straub, and J. S. Isenberg, "Nitric oxide: what's new to NO?," American Journal of Physiology. Cell Physiology, vol. 312, no. 3, pp. C254-C262, 2017.

[10] C. G. Kevil, G. K. Kolluru, C. B. Pattillo, and T. Giordano, "Inorganic nitrite therapy: historical perspective and future directions," Free Radical Biology \& Medicine, vol. 51, no. 3, pp. 576-593, 2011.

[11] G. Heusch, P. Libby, B. Gersh et al., "Cardiovascular remodelling in coronary artery disease and heart failure," The Lancet, vol. 383, no. 9932, pp. 1933-1943, 2014.

[12] B. B. Lima, M. Hammadah, J. H. Kim et al., "Association of transient endothelial dysfunction induced by mental stress with major adverse cardiovascular events in men and women with coronary artery disease," JAMA Cardiology, vol. 4, no. 10, pp. 988-996, 2019.

[13] S. Ghio, P. L. Temporelli, C. Klersy et al., "Prognostic relevance of a non-invasive evaluation of right ventricular function and pulmonary artery pressure in patients with chronic heart failure," European Journal of Heart Failure, vol. 15, no. 4, pp. 408-414, 2013.

[14] S. Rosenkranz, J. S. Gibbs, R. Wachter, T. de Marco, A. VonkNoordegraaf, and J. L. Vachiéry, "Left ventricular heart failure and pulmonary hypertension," European Heart Journal, vol. 37, no. 12, pp. 942-954, 2016. 
[15] R. Gogiraju, A. Hubert, J. Fahrer et al., "Endothelial leptin receptor deletion promotes cardiac autophagy and angiogenesis following pressure overload by suppressing Akt/mTOR signaling," Circulation: Heart Failure, vol. 12, no. 1, 2019.

[16] T. Romacho, I. Valencia, M. Ramos-Gonzalez et al., "Visfatin/eNampt induces endothelial dysfunction_in vivo_: a role for Toll- Like Receptor 4 and NLRP3 inflammasome," Scientific Reports, vol. 10, no. 1, p. 5386, 2020.

[17] X. H. Wang, L. Z. Dou, C. Gu, and X. Q. Wang, "Plasma levels of omentin-1 and visfatin in senile patients with coronary heart disease and heart failure," Asian Pacific Journal of Tropical Medicine, vol. 7, no. 1, pp. 55-62, 2014.

[18] M. Shichiri, S. Ishimaru, T. Ota, T. Nishikawa, T. Isogai, and Y. Hirata, "Salusins: newly identified bioactive peptides with hemodynamic and mitogenic activities," Nature Medicine, vol. 9, no. 9, pp. 1166-1172, 2003.

[19] L. J. Ozelius, C. E. Page, C. Klein et al., "The TOR1A (DYT1) gene family and its role in early onset torsion dystonia," Genomics, vol. 62, no. 3, pp. 377-384, 1999.

[20] H. Izumiyama, H. Tanaka, K. Egi, M. Sunamori, Y. Hirata, and M. Shichiri, "Synthetic salusins as cardiac depressors in rat," Hypertension, vol. 45, no. 3, pp. 419-425, 2005.

[21] T. Koya, T. Miyazaki, T. Watanabe et al., "Salusin- $\beta$ accelerates inflammatory responses in vascular endothelial cells via NF- $\kappa \mathrm{B}$ signaling in LDL receptor-deficient mice in vivo and HUVECs in vitro," American Journal of Physiology. Heart and Circulatory Physiology, vol. 303, no. 1, pp. H96-105, 2012.

[22] K. Sato, K. Fujimoto, T. Koyama, and M. Shichiri, "Release of salusin- $\beta$ from human monocytes/macrophages," Regulatory Peptides, vol. 162, no. 1-3, pp. 68-72, 2010.

[23] L. L. Zhang, L. Ding, F. Zhang et al., "Salusin- $\beta$ in rostral ventrolateral medulla increases sympathetic outflow and blood pressure via superoxide anions in hypertensive rats," Journal of Hypertension, vol. 32, no. 5, pp. 1059-1067, 2014.

[24] T. Watanabe, K. Nishio, T. Kanome et al., "Impact of salusinalpha and -beta on human macrophage foam cell formation and coronary atherosclerosis," Circulation, vol. 117, no. 5, pp. 638-648, 2008.

[25] Z. Wang, T. Takahashi, Y. Saito et al., "Salusin $\beta$ is a surrogate ligand of the mas-like G protein-coupled receptor MrgA1," European Journal of Pharmacology, vol. 539, no. 3, pp. 145150, 2006.

[26] M. Shichiri, D. Nonaka, L. J. Lee, and K. Tanaka, "Identification of the salusin- $\beta$ receptor using proteoliposomes embedded with endogenous membrane proteins," Scientific Reports, vol. 8, no. 1, 2018.

[27] X. S. Ren, L. Ling, B. Zhou et al., "Silencing salusin- $\beta$ attenuates cardiovascular remodeling and hypertension in spontaneously hypertensive rats," Scientific Reports, vol. 7, no. 1, p. $43259,2017$.

[28] H. J. Sun, L. L. Zhang, Z. D. Fan et al., "Superoxide anions involved in sympathoexcitation and pressor effects of salusin-beta in paraventricular nucleus in hypertensive rats," Acta Physiologica, vol. 210, no. 3, pp. 534-545, 2014.

[29] H. J. Sun, T. Y. Liu, F. Zhang et al., "Salusin- $\beta$ contributes to vascular remodeling associated with hypertension via promoting vascular smooth muscle cell proliferation and vascular fibrosis," Biochimica et Biophysica Acta (BBA) - Molecular Basis of Disease, vol. 1852, no. 9, pp. 1709-1718, 2015.

[30] H. J. Sun, M. X. Zhao, X. S. Ren et al., "Salusin- $\beta$ promotes vascular smooth muscle cell migration and intimal hyperplasia after vascular injury via ROS/NFkappaB/MMP-9 pathway," Antioxidants \& Redox Signaling, vol. 24, no. 18, pp. 10451057, 2016.

[31] H. J. Sun, M. X. Zhao, T. Y. Liu et al., "Salusin- $\beta$ induces foam cell formation and monocyte adhesion in human vascular smooth muscle cells via miR155/NOX2/NF $\kappa$ B pathway," Scientific Reports, vol. 6, no. 1, 2016.

[32] C. H. Zhou, J. Pan, H. Huang et al., "Salusin- $\beta$, but Not Salu$\sin -\alpha$, Promotes Human Umbilical Vein Endothelial Cell Inflammation via the 338 MAPK/JNK-NF- $\kappa$ B Pathway," PLoS One, vol. 9, no. 9, 2014.

[33] J. J. Teixeira-da-Silva, H. S. Nunes-Moreira, C. O. Silva et al., "Chronic administration of sildenafil improves endothelial function in spontaneously hypertensive rats by decreasing COX-2 expression and oxidative stress," Life Sciences, vol. 225, pp. 29-38, 2019.

[34] S. Sun, F. Zhang, Y. Pan et al., "A TOR2A gene product: salu$\sin -\beta$ contributes to attenuated vasodilatation of spontaneously hypertensive rats," Cardiovascular Drugs and Therapy, vol. 35, no. 1, pp. 125-139, 2021.

[35] Y. Pan, S. Sun, X. Wang et al., "Improvement of vascular function by knockdown of salusin- $\beta$ in hypertensive rats via nitric oxide and reactive oxygen species signaling pathway," Frontiers in Physiology, vol. 12, p. 622954, 2021.

[36] H. B. Li, X. J. Yu, J. Bai et al., "Silencing salusin $\beta$ ameliorates heart failure in aged spontaneously hypertensive rats by ROS-relative MAPK/NF- $\kappa$ B pathways in the paraventricular nucleus," International Journal of Cardiology, vol. 280, pp. 142-151, 2019.

[37] X. Ren, F. Zhang, M. Zhao et al., "Angiotensin-(1-7) in paraventricular nucleus contributes to the enhanced cardiac sympathetic afferent reflex and sympathetic activity in chronic heart failure rats," Cellular Physiology and Biochemistry, vol. 42, no. 6, pp. 2523-2539, 2017.

[38] S. Zhang, F. Zhang, H. Sun, Y. Zhou, and Y. Han, "Enhanced sympathetic activity and cardiac sympathetic afferent reflex in rats with heart failure induced by adriamycin," Journal of Biomedical Research, vol. 26, no. 6, pp. 425-431, 2012.

[39] F. Zhang, H. Tang, S. Sun et al., "Angiotensin-(1-7) induced vascular relaxation in spontaneously hypertensive rats," Nitric Oxide, vol. 88, pp. 1-9, 2019.

[40] H. J. Sun, H. Zhou, X. M. Feng et al., "Superoxide anions in the paraventricular nucleus mediate cardiac sympathetic afferent reflex in insulin resistance rats," Acta Physiologica, vol. 212, no. 4, pp. 267-282, 2014.

[41] Q. B. Lu, J. Sun, Y. Kang et al., "Superoxide anions and NO in the paraventricular nucleus modulate the cardiac sympathetic afferent reflex in obese rats," International Journal of Molecular Sciences, vol. 19, no. 1, 2018.

[42] L. Ding, Y. Kang, H. B. Dai et al., "Adipose afferent reflex is enhanced by $\mathrm{TNF} \alpha$ in paraventricular nucleus through NADPH oxidase-dependent ROS generation in obesityrelated hypertensive rats," Journal of Translational Medicine, vol. 17, no. 1, p. 256, 2019.

[43] J. Simon, E. Nemeth, A. Nemes et al., "Circulating relaxin-1 level is a surrogate marker of myocardial fibrosis in HFrEF," Frontiers in Physiology, vol. 10, p. 690, 2019.

[44] R. Verjans, T. Peters, F. J. Beaumont et al., "MicroRNA$221 / 222$ family counteracts myocardial fibrosis in pressure overload-induced heart failure," Hypertension, vol. 71, no. 2, pp. 280-288, 2018. 
[45] A. P. Kusumbe, S. K. Ramasamy, T. Itkin et al., "Age-dependent modulation of vascular niches for haematopoietic stem cells," Nature, vol. 532, no. 7599, pp. 380-384, 2016.

[46] Y. Han, Z. Shi, F. Zhang et al., "Reactive oxygen species in the paraventricular nucleus mediate the cardiac sympathetic afferent reflex in chronic heart failure rats," European Journal of Heart Failure, vol. 9, no. 10, pp. 967-973, 2007.

[47] M. X. Zhao, B. Zhou, L. Ling et al., "Salusin- $\beta$ contributes to oxidative stress and inflammation in diabetic cardiomyopathy," Cell Death \& Disease, vol. 8, no. 3, p. e2690, 2017.

[48] N. Suzuki, M. Shichiri, T. Tateno, K. Sato, and Y. Hirata, "Distinct systemic distribution of salusin- $\alpha$ and salusin- $\beta$ in the rat," Peptides, vol. 32, no. 4, pp. 805-810, 2011.

[49] K. Sato, T. Sato, T. Susumu, T. Koyama, and M. Shichiri, "Presence of immunoreactive salusin- $\beta$ in human plasma and urine," Regulatory Peptides, vol. 158, no. 1-3, pp. 63-67, 2009.

[50] N. Suzuki, M. Shichiri, T. Akashi et al., "Systemic distribution of salusin expression in the rat," Hypertension Research, vol. 30, no. 12, pp. 1255-1262, 2007.

[51] J. Liu, Y. G. Ren, L. H. Zhang, Y. W. Tong, and L. Kang, "Serum salusin- $\beta$ levels are associated with the presence and severity of coronary artery disease," Journal of Investigative Medicine, vol. 63, no. 4, pp. 632-635, 2015.

[52] K. Fujimoto, A. Hayashi, Y. Kamata et al., "Correction: Circulating levels of human salusin- $\beta$, a potent hemodynamic and atherogenesis regulator," PLoS One, vol. 8, no. 11, 2013.

[53] W. W. Chen, H. J. Sun, F. Zhang et al., "Salusin- $\beta$ in paraventricular nucleus increases blood pressure and sympathetic outflow via vasopressin in hypertensive rats," Cardiovascular Research, vol. 98, no. 3, pp. 344-351, 2013.

[54] H. J. Sun, D. Chen, P. Y. Wang et al., "Salusin- $\beta$ Is Involved in Diabetes Mellitus-Induced Endothelial Dysfunction via Degradation of Peroxisome Proliferator-Activated Receptor Gamma," Oxidative Medicine and Cellular Longevity, vol. 2017, Article ID 6905217, 14 pages, 2017.

[55] X. Zhu, Y. Zhou, W. Cai, H. Sun, and L. Qiu, "Salusin- $\beta$ mediates high glucose-induced endothelial injury via disruption of AMPK signaling pathway," Biochemical and Biophysical Research Communications, vol. 491, no. 2, pp. 515-521, 2017.

[56] M. Karin and M. Delhase, "The I $\kappa$ B kinase (IKK) and NF- $\kappa$ B: key elements of proinflammatory signalling," Seminars in Immunology, vol. 12, no. 1, pp. 85-98, 2000.

[57] K. Toczylowski, T. Hirnle, D. Harasiuk et al., "Plasma concentration and expression of adipokines in epicardial and subcutaneous adipose tissue are associated with impaired left ventricular filling pattern," Journal of Translational Medicine, vol. 17, no. 1, 2019.

[58] N. Katsiki, D. P. Mikhailidis, and M. Banach, "Leptin, cardiovascular diseases and type 2 diabetes mellitus," Acta Pharmacologica Sinica, vol. 39, no. 7, pp. 1176-1188, 2018.

[59] S. Becerril, A. Rodriguez, V. Catalan et al., "Functional relationship between leptin and nitric oxide in metabolism," Nutrients, vol. 11, no. 9, p. 2129, 2019.

[60] P. Wang, T. Y. Xu, Y. F. Guan, D. F. Su, G. R. Fan, and C. Y. Miao, "Perivascular adipose tissue-derived visfatin is a vascular smooth muscle cell growth factor: role of nicotinamide mononucleotide," Cardiovascular Research, vol. 81, no. 2, pp. 370-380, 2009.

[61] M. Esfahani, M. Saidijam, R. Najafi, M. T. Goodarzi, and A. Movahedian, "The effect of salusin- $\beta$ on expression of pro- and anti-inflammatory cytokines in human umbilical vein endothelial cells (HUVECs)," ARYA Atherosclerosis, vol. 14, no. 1, pp. 1-10, 2018.

[62] E. Panieri and M. M. Santoro, "ROS signaling and redox biology in endothelial cells," Cellular and Molecular Life Sciences, vol. 72, no. 17, pp. 3281-3303, 2015.

[63] C. M. Sag, M. Schnelle, and A. M. Shah, "Response by Sag et al to letter regarding article, "Distinct regulatory effects of myeloid cell and endothelial cell NAPDH oxidase 2 on blood pressure"," Circulation, vol. 136, no. 21, pp. 2090-2091, 2017.

[64] Y. Yin, Z. Zhou, W. Liu, Q. Chang, G. Sun, and Y. Dai, "Vascular endothelial cells senescence is associated with NODlike receptor family pyrin domain-containing 3 (NLRP3) inflammasome activation via reactive oxygen species (ROS)/thioredoxin-interacting protein (TXNIP) pathway," The International Journal of Biochemistry \& Cell Biology, vol. 84, pp. 22-34, 2017.

[65] A. Aneja, W. H. Tang, S. Bansilal, M. J. Garcia, and M. E. Farkouh, "Diabetic cardiomyopathy: insights into pathogenesis, diagnostic challenges, and therapeutic options," The American Journal of Medicine, vol. 121, no. 9, pp. 748-757, 2008.

[66] B. K. Pedersen, "Anti-inflammatory effects of exercise: role in diabetes and cardiovascular disease," European Journal of Clinical Investigation, vol. 47, no. 8, pp. 600-611, 2017.

[67] E. Sinagra, G. Perricone, C. Romano, and M. Cottone, "Heart failure and anti tumor necrosis factor-alpha in systemic chronic inflammatory diseases," European Journal of Internal Medicine, vol. 24, no. 5, pp. 385-392, 2013.

[68] M. I. Danila, N. M. Patkar, J. R. Curtis, K. G. Saag, and G. G. Teng, "Biologics and heart failure in rheumatoid arthritis: are we any wiser?," Current Opinion in Rheumatology, vol. 20, no. 3, pp. 327-333, 2008.

[69] P. Reventun, M. Alique, I. Cuadrado et al., "iNOS-derived nitric oxide induces integrin-linked kinase endocytic lysosomemediated degradation in the vascular endothelium," Arteriosclerosis, Thrombosis, and Vascular Biology, vol. 37, no. 7, pp. 1272 1281, 2017.

[70] R. Chen, M. Iwai, L. Wu et al., "Important role of nitric oxide in the effect of angiotensin-converting enzyme inhibitor imidapril on vascular injury," Hypertension, vol. 42, no. 4, pp. $542-547,2003$. 